Running head: JURORS' JUDGMENTS IN CASES INVOLVING JUVENILE DEFENDANTS

Accepted for publication in Psychology, Public Policy, and Law on March 9, 2011

Understanding Jurors' Judgments in Cases Involving Juvenile Defendants:

Effects of Confession Evidence and Intellectual Disability

Cynthia J. Najdowski, M.A.

Bette L. Bottoms, Ph.D.*

University of Illinois at Chicago

Acknowledgments. We thank Professors James R. Larson, Jr., Allison D. Redlich, and Linda J. Skitka for their helpful suggestions on this project; Maria Vargas, Megan Cummens, Ilse Salinas, and Krupa Patel for their research assistance; Alison Perona for legal expertise and consultation on jury instructions; and Court TV for donating the trial videotape from which the stimulus trial materials were constructed. This research was supported by an American Psychology-Law Society Grant-in-Aid and a Psi Chi Graduate Research Grant. Portions of this research were presented at the 2009 annual meeting of the American Psychology-Law Society.

*Corresponding author: Department of Psychology, 1007 West Harrison Street (M/C 285), Chicago, IL 60607-7137. 


\begin{abstract}
Juveniles are at heightened risk for falsely confessing to crimes, particularly if they are intellectually disabled. We conducted a mock trial experiment to investigate the effects of a juvenile defendant's confession and status as intellectually disabled on jurors' decision making. As expected, jurors discounted a juvenile's coerced confession: Jurors' judgments were similar for a juvenile who was perceived to have confessed under coercion and a juvenile who did not confess. In general, these effects were explained by the fact that, compared to a juvenile who was perceived as having confessed voluntarily, a juvenile who was perceived as having confessed under coercion was seen as more suggestible and less likely to have confessed truthfully. These perceptions led jurors to feel more sympathy and less anger toward the juvenile who confessed under coercion, and ultimately render more pro-defense judgments for her. The juvenile's disability status did not moderate these effects, nor did it influence jurors' verdicts nor suspicions of guilt. Jurors who suspected the juvenile was guilty, however, were less likely to vote guilty and less likely to think it was appropriate for the trial to be held in adult court when the juvenile was perceived as intellectually disabled rather than nondisabled, partially because they thought the disabled juvenile was less criminally deviant and less able to control her behavior and because they had more sympathy for her. Implications for psychological theory and public policy are discussed.

Keywords: juror decision making, juvenile defendants, confessions, intellectual disability, attribution theory
\end{abstract}




\section{Understanding Jurors’ Judgments in Cases Involving Juvenile Defendants: Effects of Confession Evidence and Intellectual Disability}

There are stunning examples of juveniles falsely confessing to crimes. For instance, in the infamous Central Park jogger case, five 14- to 16-year-old boys all separately falsely confessed and were convicted of brutally beating and raping a woman they had not touched (Drizin \& Leo, 2004). Those boys were of average intelligence, but there are also many examples of false confessions from juveniles with lower than average IQs. Consider Lacresha Murray, an 11-year-old with an IQ of 77: After denying allegations over 40 times, Murray eventually succumbed to police pressure and falsely confessed to murdering a toddler (Drizin \& Colgan, 2004; Redlich, Quas, \& Ghetti, 2008). Research has confirmed what these cases suggest: Juveniles are at heightened risk for falsely confessing to crimes they did not commit, particularly if they are intellectually disabled (i.e., have IQs below 70) (Kassin et al., 2010). For example, Goldstein, Condie, Kalbeitzer, Osman, and Geier (2003) found that $67 \%$ of boy offenders stated that they were inclined to or would definitely falsely confess in response to hypothetical interrogations involving common police pressure tactics (e.g., sympathy, intimidation). In actual cases, approximately $35 \%$ of proven false confessors are juveniles and 25\% are intellectually disabled (Drizin \& Leo, 2004; Leo \& Ofshe, 1998).

In the present research, we examine jurors' judgments in cases involving juvenile defendants who have confessed and who are intellectually disabled. This investigation is important because juveniles are entitled to a jury trial in juvenile court in some states (e.g., Kansas; In re L. M., 2008) and increasingly likely to be tried by jurors in adult criminal court (for review, see Reppucci, Michel, \& Kostelnik, 2009). Jurors are often trusted to evaluate the voluntariness of a confession and to remain impartial if they deem that a confession was coerced (see Lego v. Twomy, 1972; Kasimar, LaFave, \& Israel, 1994). Considering that juveniles might falsely confess to crimes they did not commit, particularly if they are disabled, this study aims to determine whether this trust in jurors is justified or misguided. 


\section{The Impact of Confessions on Jurors’ Judgments}

Mock trial research has revealed that jurors do not dismiss adults' coerced confessions: Jurors are consistently more likely to convict an adult who was coerced to confess and then recanted compared to an adult who never confessed (e.g., Kassin \& McNall, 1991; Kassin \& Sukel, 1997; Kassin \& Wrightsman, 1981; Woody \& Forrest, 2009). Why? To begin with, although potential jurors recognize that interrogation tactics are coercive (Chojnacki, Cicchini, \& White, 2008; Henkel, Coffman, \& Dailey, 2008; Leo \& Liu, 2009), they generally believe such tactics are necessary to elicit truthful confessions (Henkel et al., 2008; Leo \& Liu, 2009) and unlikely to elicit false ones (Leo \& Liu, 2009). Also, people generally cannot imagine themselves ever falsely confessing to a crime (Henkel et al., 2008; Woody \& Forrest, 2009). Finally, people are not adept at distinguishing truthful and false confessions (Kassin, Meissner, \& Norwick, 2005). For all of these reasons, adults' false confessions are extremely persuasive (see Kassin et al., 2010, for review).

Some research suggests that jurors are also biased to believe juveniles' confessions. For example, less than half of potential jurors realize that juveniles are at risk for confessing falsely (41\%, Henkel et al., 2008; 43\%, Chojnacki et al. 2008), although more jurors are sensitive to this risk when asked explicitly about children younger than 10 years old (55\%, Henkel et al., 2008). In Redlich, Ghetti, and Quas (2008), mock jurors were twice as likely to determine that a boy was involved in a crime when he confessed and recanted compared to when he never admitted involvement, regardless of the boy's age $(7,11$, or 14 years old). In contrast to research on perceptions of adult's confessions, however, Najdowski, Bottoms, and Vargas (2009; Study 2) found that mock jurors were more likely to convict a juvenile defendant when she confessed voluntarily than when she confessed under coercion from a police interrogator or when she did not confess. Further, Najdowski et al. demonstrated that jurors were no more likely to convict a juvenile when she confessed under coercion compared to when she did not confess.

Why might jurors discount juveniles' coerced confessions? We theorize that the extent to 
which jurors are influenced by a juvenile's confession is determined by how suggestible they perceive the juvenile to be. In support, the majority of jurors are aware that juveniles are suggestible (Quas, Thompson, \& Clarke-Stewart, 2005) and that suggestible individuals are in danger of falsely confessing (Henkel et al., 2008). Further, Najdowski et al. (2009) found that mock jurors perceived a juvenile who was coerced to confess as more suggestible than a juvenile who confessed voluntarily or never confessed. Also, Redlich, Quas, and Ghetti (2008) found that mock jurors who read about the Lacresha Murray case described previously were less likely to vote guilty the less they thought the juvenile understood what was happening in the interview and the more unfair they perceived the police to have been.

Attribution theory (Weiner, 2006) is also useful for understanding the mechanisms underlying the influence of confession voluntariness on jurors' judgments. According to theory, jurors make causal attributions for behavior based on locus (i.e., whether the factors that caused an event are internal versus external to a person). In general, the biasing effect of confessions has been credited to jurors' tendency to attribute the cause of a confession to internal factors (i.e., actual guilt) and to dismiss external factors (e.g., coercion, the stress of interrogation) (Kassin \& Gudjonsson, 2004). But according to Kelley’s (1973) discounting principle, internal attributions are discounted or given less weight when external attributions are more plausible. In addition, attributions are usually made to the most salient plausible cause of which perceivers are aware (Kelley \& Michela, 1980). Thus, we theorize that coercive interrogation conditions highlight a juvenile's suggestibility (e.g., Najdowski et al., 2009) and decrease the likelihood that jurors will make internal attributions for a juvenile's confession (i.e., that the confession is true) relative to when an interrogation is noncoercive. In support, when allegations are derived from suggestive interviewing techniques, adults perceive children's disclosures and testimony concerning abuse as less believable (Castelli, Goodman, \& Ghetti, 2005; Laimon \& Poole, 2008). Also, jurors in the Najdowski et al. study rated a juvenile's confession as significantly less truthful when it was 
coerced compared to voluntary. Because internal attributions increase perceptions that a person is responsible for an outcome, which, in turn, lead to diminished sympathy and heightened anger in the context of justice-related decisions (Shaver, 1985; Weiner, 2006), it is also possible that jurors who do not make internal attributions for a confession feel more sympathy and less anger for a juvenile than other jurors. Ultimately, such affective reactions might translate into more pro-defense judgments for a juvenile who confessed under coercion than a juvenile who confessed voluntarily.

Although only a minority of potential jurors recognize the heightened risk of false confessions among juveniles, most recognize this risk among individuals who are mentally impaired (Chojnacki et al., 2008; Henkel et al., 2008). In fact, in the Najdowski et al. (2009) study, the finding that mock jurors discounted a juvenile defendant's coerced confession depended on the disability status of the juvenile: Jurors completely discounted a juvenile's coerced confession only when she was portrayed as disabled, not when she was portrayed as having average intelligence. Perhaps this is because jurors in that study perceived the disabled juvenile as more suggestible (i.e., less understanding of the interrogation, more vulnerable to coercion) than the nondisabled juvenile. Also, according to the patronization effect (Gibbons, Sawin, \& Gibbons, 1979), people tend to attribute behavior less to internal than external factors and attribute less responsibility for disabled compared to nondisabled individuals, presumably because they believe that disabled individuals are incompetent and have little control over their lives. Thus, jurors might be more likely to believe that a juvenile's confession was coerced (an external explanation) when she is disabled rather than nondisabled. Najdowski et al. found some support for this hypothesis: Jurors' perceptions of the truthfulness of a juvenile's confession were not affected directly by her disability status, but jurors did perceive the police as less fair and more coercive when the juvenile was disabled compared to nondisabled.

\section{The Impact of Juveniles’ Intellectual Disability on Jurors’ Judgments}

We were interested primarily in testing whether the effects of confession evidence on jurors' judgments would be moderated by a juvenile defendant's disability status, but there is good reason 
to study jurors' perceptions of disabled juveniles in their own right. To begin with, $7 \%$ to $15 \%$ of delinquent youth are intellectually disabled (Kazdin, 2000) and even more are borderline disabled (i.e., IQs ranging from 71-84) (see, e.g., Goldstein et al., 2003; Viljoen, Klaver, \& Roesch, 2005). The U.S. Supreme Court banned capital punishment for juveniles and intellectually disabled adults (Atkins v. Virginia, 2002; Roper v. Simmons, 2005), reasoning that their diminished cognitive and psychosocial capacities diminish their legal culpability. Such deficits are likely exacerbated in defendants who are both young and disabled, but it is unclear whether jurors recognize this when determining their legal culpability. Research suggests that jurors use intellectual disability as a mitigating factor in cases involving adult defendants (Garvey, 1998; Gibbons, Gibbons, \& Kassin, 1981). In one of only two studies examining whether this mitigating effect extends to cases involving juveniles, Najdowski et al. (2009; Study 2) found that mock jurors perceived a disabled juvenile as less deviant, less responsible, and less guilty than a nondisabled juvenile when she was accused of a relatively minor drug offense but not for more serious crimes (i.e., assault, murder). Jurors might find it more plausible that a disabled juvenile committed a less serious offense than a more serious offense. In support, mock jurors in Gibbons et al.'s (1981) study believed a disabled adult was more likely than a nondisabled adult to have committed vandalism, but less likely to have committed burglary and assault. Perhaps disabled individuals are perceived as less cognitively sophisticated than nondisabled individuals, and therefore less capable of planning and carrying out a complex crime. Jurors might find it implausible that a juvenile is truly disabled when she is on trial in adult court for a serious crime (Levine, Williams, Sixt, \& Valenti, 2001).

Even so, evidence is mixed and, theoretically, one would expect jurors' judgments to be affected by a juvenile defendant's disability status. According to attribution theory (Weiner, 2006), in addition to making causal attributions for a transgressor's behavior based on locus, jurors make attributions regarding the controllability (i.e., whether a person does or does not possess the ability to affect a cause) and stability (i.e., whether a cause is changing or unchanging over time) of the 
behavior. Just as making fewer internal attributions reduces how responsible a defendant is perceived to be, so do less controllable and less stable attributions. Jurors' subsequent affective reactions in turn affect their motivations for sentencing a defendant, with more sympathy and less anger leading to sentencing goals that are more rehabilitation-focused but less retribution-focused. Indeed, after making initial guilt judgments, mock jurors in Gibbons et al.'s (1981) study were asked to assume that the adult had committed the crime. Jurors attributed the cause of the crime less to internal factors (i.e., financial need, inherent criminal character) and more to external factors (i.e., coercion by another person) for a disabled adult than a nondisabled adult. Jurors who made more external attributions recommended less severe sentences, and jurors perceived a disabled adult as less likely to recidivate and less deserving of a severe sentence than a nondisabled adult. The researchers explained their findings with the patronization effect (Gibbons et al., 1979), discussed previously. In line with this theory as well as Kelley’s (1973) discounting principle, Najdowski et al. (2009; Study 1) found that, even when it was clear that a juvenile committed a crime, regardless of the type of crime, jurors perceived her as less deviant and less responsible for her actions (but not more amenable to rehabilitation) when she was disabled rather than nondisabled. Jurors were also more likely to think that a juvenile committed aggravated murder (but not less serious crimes) because of external factors (i.e., the juvenile's background) when she was disabled compared to nondisabled. According to theory, when jurors perceive that disabled defendants are too incompetent to execute complex crimes, they might search for external explanations. Thus, jurors who suspect that a juvenile committed a crime might make more external, uncontrollable, and unstable attributions for the causes of a crime when a juvenile is disabled compared to nondisabled. Such attributions might translate into perceptions that a disabled juvenile is less responsible than a nondisabled juvenile, and increase sympathy and rehabilitative sentencing goals while decreasing anger and retributive sentencing goals. Ultimately, this sequence could produce more pro-defense case judgments for a disabled juvenile than a nondisabled juvenile. 


\section{Overview and Hypotheses}

This study conformed to a 3 (confession evidence: no confession, coerced confession, voluntary confession) X 2 (juvenile defendant disability status: intellectually disabled, nondisabled) between-subjects experimental design. We sought to test the effects of confession evidence and disability status on mock jurors' judgments for a juvenile defendant and to identify the psychological mechanisms that would explain the effects. Based on prior research and theory (e.g., Kassin \& Gudjonsson, 2004; Kelley, 1973; Najdowski et al., 2009; Redlich, Quas, \& Ghetti, 2008; Weiner, 2006), we predicted that jurors would be sensitive to a juvenile's vulnerability to falsely confess by rendering (a) more pro-defense judgments for either a juvenile who did not confess or a juvenile who confessed under coercion compared to a juvenile who confessed voluntarily and (b) similar judgments for a juvenile who did not confess and a juvenile who confessed under coercion. We further hypothesized that the effect of confession voluntariness (i.e., coerced, voluntary) on jurors' judgments would be mediated sequentially by jurors' increased perceptions of suggestibility for a juvenile who confessed under coercion compared to voluntarily, decreased likelihood that jurors would make internal attributions for the coerced confession (i.e., jurors would be less likely to believe the confession), and increased sympathy and decreased anger for the juvenile. Based on prior theory and research (e.g., Gibbons et al., 1979; 1981; Najdowski et al., 2009; Weiner, 2006), we also predicted that the tendency for mock jurors' judgments to be more pro-defense when a juvenile confessed under coercion compared to voluntarily would be especially prominent when the juvenile was disabled rather than nondisabled. We also expected to find a main effect of disability status such that jurors would render more pro-defense case judgments for a disabled juvenile than a nondisabled juvenile. We predicted that, for jurors who suspected that a juvenile committed a crime, this effect would be mediated sequentially by jurors' (a) tendency to make more external, uncontrollable, and unstable attributions for the causes of the crime; (b) perceptions of the juvenile as less responsible; (c) feeling more sympathy and less anger; and (d) endorsement of more 
rehabilitative and less retributive sentencing goals when the juvenile was disabled compared to nondisabled.

\section{Method}

\section{Participants}

Participants were 270 jury-eligible undergraduate psychology students ( $36 \%$ men) who participated in exchange for course credit. The sample was all U.S. citizens, young $(M=19, S D=2$, ranging from 18 to 29 years old), and ethnically diverse (46\% Caucasian, 28\% Asian, 15\%

Hispanic, 7\% African American, and 4\% of other backgrounds). In addition to these 270 participants, 25 participants were dropped from the study: 4 who failed the age manipulation check, 16 who missed the confession manipulation check, and 5 who failed the disability status manipulation check.

\section{Materials}

Trial stimuli. Written and video materials were based on an actual adult criminal court trial involving a 16-year-old Caucasian girl accused of murdering her father (Kentucky v. English, 1991, in American Lawyer/Court TV Video Library Service, 1991). The juvenile's age was changed to 15 years, but many other facts were retained. The materials provided jurors with information about the juvenile defendant, the case, and testimony from the juvenile, her school psychologist, her friend, and her aunt. These materials were used to manipulate confession evidence and disability status.

Video clips. Two video clips were used. In the first, which was approximately $1.5 \mathrm{~min}$ long, a narrator described the juvenile's age as 15 years, the crime she was accused of (murder of her father), that the juvenile was being tried in adult court "based on the severity of the charges," and the juvenile's social and family background (lower to middle class, her parents' divorced and she "bounced between them," current living situation with her older siblings, no known history of abuse

or neglect). Two versions of this clip were used to manipulate defendant disability status, which was introduced through the narrator's description of testimony from the juvenile's school psychologist. 
In the disabled condition, the psychologist asserted that the juvenile (a) had a lower than average IQ and was "developmentally delayed, functioning in the mild range of mental retardation"; (b) performed poorly in school; and (c) did "not have the reasoning abilities of a normal 15-year-old." In the nondisabled condition, the psychologist asserted that the juvenile (a) was "of average intelligence with no major psychological problems," (b) performed well in school, and (c) had "the reasoning abilities of a normal 15-year-old." (Using edited portions of the same video, Bottoms, Nysse-Carris, Harris, and Tyda, 2003, demonstrated that differential reactions to a juvenile abuse victim could be elicited merely by labeling the juvenile as "mildly mentally retarded" compared to "having average intelligence" even when participants viewed the same individual. In fact, the girl had failed 3 grades in school and appears somewhat "slow" during her testimony.)

The second clip, seen after the participants read the written scenario described below, presented approximately 30-45 s of the juvenile's actual testimony. Three versions of this clip were used to manipulate the confession evidence variable. In all three versions, the clip showed the juvenile discussing several phone calls she placed after the alleged crime. In the coerced-confession and voluntary-confession conditions (but not the no-confession condition), the clip included an additional segment showing a question from the defense attorney about the juvenile retracting a confession and the juvenile's reply. (In the actual trial, the juvenile also testified about a confession she made, but later retracted.) In both confession conditions, the juvenile stated that she confessed because she "didn't know what to do." In the coerced-confession condition, she also emphasized that she confessed because she was upset and scared.

Written case summary. Six versions of the written case summary were also used to accommodate the manipulations of confession evidence and disability status. The summary began by repeating the video narrator's description of the juvenile, including the disability status manipulation. Then, participants read that (a) the juvenile's father came home drunk and went to his room, (b) the next thing the juvenile remembered was seeing him lying in a pool of blood on his bed 
with a gun nearby, (c) the juvenile made some calls to try to get help, (d) the defense argued that the juvenile's father was depressed and killed himself, (e) forensic evidence was inconclusive, (f) the juvenile's friend testified that she had witnessed the juvenile fighting with her father on the day of the shooting, and $(\mathrm{g})$ the juvenile's aunt testified that the juvenile had a tumultuous relationship with her father and further noted that the juvenile stood to inherit $\$ 100,000$ from his death. The aunt's testimony was used to reinforce the disability manipulation. In the disabled condition, the aunt stated, "I understand she's retarded, but she's still a spoiled brat, if you ask me.” In the nondisabled condition, the aunt stated, "Tracie was a spoiled brat, if you ask me."

The confession manipulation was introduced at the end of the written case summary by varying a description of the interrogation and statements made by a detective and the juvenile defendant. In the no-confession condition, the juvenile maintained her innocence throughout the interrogation. In the voluntary-confession condition, the juvenile confessed immediately upon questioning, and the detective testified that he rejected any suggestion that the confession was coerced, saying that she "just blurted it out. Nobody twisted her arm. No one was abusing her or threatening her or anything. She wasn't even handcuffed." In the coerced-confession condition, she confessed after 7 hours of coercive questioning during which the detective used minimization techniques (i.e., offered sympathy, justified the crime) and lied to the juvenile about having evidence against her (i.e., a security video). The detective conceded that the juvenile was "under stress while in custody," and he admitted that he had lied to the juvenile about evidence, but he still argued that the stress had nothing to do with the confession, saying "She just blurted it out. It was a standard interrogation. She was handcuffed, but that's pretty typical." This manipulation is virtually identical to that used successfully in Najdowski et al.'s (2009) Study 2 murder condition, which was modeled after a manipulation used successfully by Kassin and Sukel (1997). The summaries were otherwise identical. Pilot testing confirmed that the juvenile's actual guilt or innocence was relatively ambiguous (i.e., the conviction rate averaged across all conditions was 52\%). 
Jury instructions. All jurors received the exact same instructions that Illinois jurors receive in first-degree murder cases. The instructions described the burden of proof and elements necessary to find the juvenile guilty. Jurors in the confession conditions also received instructions used in cases involving a confession, which state that, "In determining the weight to be given to a statement, you should consider all of the circumstances under which it was made."

\section{Measures.}

Demographic questionnaire. Mock jurors were asked to provide their age, citizenship status, gender, and ethnicity.

Verdict and suspicion judgments. Because the verdict is the most important decision in actual cases, jurors were first asked, "What is your verdict in this case? Do you find the defendant, Tracie English, Guilty or Not Guilty of first degree murder?” (guilty, not guilty). Jurors' also rendered suspicion judgments by answering, "Regardless of your legal verdict above, do you think or suspect that Tracie English killed her father" (yes, no).

Trial venue and sentencing recommendations. As a proxy for public support of juvenile transfer policies, research has examined jurors' beliefs about whether a juvenile should be tried in juvenile court or adult criminal court (e.g., Nunez et al., 2007; Stalans \& Henry, 1994). Drawing from that research, jurors made trial venue recommendations by responding to the question, "Do you think Tracie English should have been tried in Adult Criminal Court or do you think she should have been sent to Juvenile Court?" (juvenile court, adult court).

Jurors in some jurisdictions render sentencing decisions, so participants who voted guilty were asked to recommend the best juvenile court sentence: "Imagine if the case had been handled in Juvenile Court. What do you think the best outcome would have been for Tracie English in this case?” (probation, psychological treatment, imprisonment). Only 3 jurors recommended a juvenile court sentence of probation, so we collapsed probation and psychological treatment into one category and compared the frequency of recommendations for those sentences to recommendations 
for imprisonment. Jurors also recommended the best adult court sentence: "Regardless of what you just answered, this case was handled in Adult Criminal Court. What do you think the best punishment is for Tracie English, the defendant, in this case?" (probation, imprisonment).

Mediating constructs. A number of statements assessed potential mediating processes on a 6-point Likert scale ranging from -3 (strongly disagree) to +3 (strongly agree) with no midpoint. Values were transformed to create a scale ranging from 1 (strongly disagree) to 6 (strongly agree).

Confession-related judgments. The perceived suggestibility scale $(\alpha=.76)$ comprised 4 items modeled after measures used by Bottoms et al. (2003), Najdowski et al. (2009), Redlich, Ghetti, and Quas (2008), and Redlich, Quas, and Ghetti (2008): "During the questioning by Detective Burbrink, Tracie English...” (a) “...was suggestible; that is, she was vulnerable to being coerced to say something that wasn't true;" (b) “...understood the questions being asked;” (c) “...understood the purpose of the interview;" and (d) "...understood that she could remain silent." The last three items were reverse-scored with higher values equal to greater suggestibility.

Jurors in the coerced-confession and voluntary-confession conditions also made a dichotomous perceived confession truthfulness judgment: "Regardless of whether you think Tracie English confessed voluntarily or whether you think her confession was coerced by Detective Burbrink, do you think her confession was truthful? That is, do you think Tracie English confessed because she was guilty?" (yes, no). This item was based on measures used by Kassin and colleagues (e.g., Kassin \& McNall, 1991; Kassin \& Sukel, 1997).

Affective reactions, attributions and perceived responsibility for the crime, and sentencing goals. Following Bottoms et al. (2003) and Haegerich and Bottoms (2000), jurors' affective reactions to the juvenile were assessed with a three-item sympathy scale ("I feel sorry for Tracie English, the defendant," "I have sympathy for Tracie English," and "I feel pity for Tracie English"; $\alpha=.89$ ) and an anger item ("I feel angry at Tracie English, the defendant").

Seven items, modeled on those used by Gibbons et al. (1981), Graham et al. (1997), 
Najdowski et al. (2009), and Pittman and Pittman (1980), assessed jurors' causal attributions for the juvenile's criminal behavior. These were completed by only participants who suspected that the juvenile was guilty, regardless of their verdicts. First, one item assessed external attributions: "Some kind of external influence (such as the situation she was in) probably caused Tracie English, the defendant, to commit this crime." Second, an internal attributions scale $(\alpha=.67)$ comprised two items: "Tracie English committed this crime because she is a bad person," and "It is in Tracie English's character to kill her father-it's just the kind of person she is." Third, an attributions of causal control scale $(\alpha=.70)$ was constructed from two items: "Tracie English could have controlled her behavior the night of her father's death," and "Tracie English had little control over her behavior and couldn’t stop herself from killing Bill English” (reverse-scored). Fourth, attributions of causal stability were assessed with one item: "Without being punished, Tracie English, the defendant, is very likely to engage in criminal behavior again in the future."

The perceived responsibility scale $(\alpha=.98)$ was composed of three items modeled after measures used by Bottoms and colleagues (Haegerich \& Bottoms, 2000; Najdowski et al., 2009): (a) "I blame Tracie English, the defendant, for her father's death"; (b) "Bill English's death is Tracie English's fault”; and (c) “Tracie English was responsible for Bill English's death.” All jurors completed this measure, but it was analyzed for only jurors who suspected the juvenile was guilty, regardless of their verdicts.

Finally, jurors who voted guilty and rendered sentences responded to two items that assessed the extent to which those sentences were based on a rehabilitative sentencing goal ("Tracie English should receive this sentence so that she will be rehabilitated and become a productive member of society") or a retributive sentencing goal ("Tracie English should receive this sentence because she deserves to suffer as she made others suffer"). These items were modeled on measures used by Darley, Carlsmith, and Robinson (2000) and Graham et al. (1997).

Manipulation checks. To ensure that jurors paid attention to the important elements of the 
case materials, they were asked to recall the defendant's age ("According to the materials you read, how old was the defendant, Tracie English, in this case"), the circumstances of her confession ("Which one of these statements is true about the police interview with the defendant, Tracie English?"; maintained her innocence, confessed immediately but took it back later, confessed after hours of questioning and false evidence and took it back later), and her disability status ("How was the defendant, Tracie English, described in the video and case materials?"; average intelligence, mildly mentally retarded).

Perceived variables measures. In addition to using manipulation checks to understand whether participants noticed a manipulation, we also included measures of what jurors actually believed about the manipulated variables. In other words, we assessed, beyond whether jurors noticed the manipulations, whether they really internalized them. First, we assessed perceived confession voluntariness. We asked jurors in the confession conditions, "Why do you think Tracie English, the defendant, confessed to the crime?" (Tracie confessed voluntarily, Tracie confessed because she was coerced by Detective Burbrink to say she committed the crime). Second, we assessed perceived disability status by asking jurors, "While you were making your case judgments, how did you think of Tracie English?” (as having normal or average intelligence, as being mildly mentally retarded).

\section{Procedure}

In exchange for course credit, students participated in the study alone or in mixed-gender groups of 2 to 10 . They were randomly assigned to experimental condition, except that there were approximately equal numbers of men and women in each condition. After being instructed about the importance of the research and the seriousness of their role as jurors, participants provided informed consent.

Next, participants were introduced to the juvenile defendant by viewing the first video clip, which was described as "media coverage" of the case that they were going to read about. This clip 
included the first manipulation of disability status. At the end of the clip, the video was frozen on a still image of the juvenile, which remained on the screen while participants read the written case summary. The summary reiterated and reinforced the disability status manipulation, and also introduced the confession evidence manipulation. Participants then viewed the second video clip showing the juvenile's actual testimony. Participants were told that they were watching a segment of the juvenile's testimony to introduce them to the defendant so they could "get a feel for what she's like." This clip also included testimony that was used to manipulate confession evidence. Participants were then asked to re-read the case summary.

Then, participants were given a copy of the Illinois pattern jury instructions to read along as the instructions were read aloud to them. Next, participants individually completed the measures. Although participants were initially told that they would deliberate with other jurors, this instruction was in place only to reinforce the seriousness of the task: Jurors did not actually deliberate. This was explained to jurors, who were then thanked and debriefed.

\section{Results}

There were 41 to 52 participants in each of the experimental cells. Log-linear modeling and chi-square analyses examined the effects of confession evidence and disability status on dichotomous judgments. In log-linear models, one level of the variable is set as the reference group to which other levels of the variable are compared. To test effects of confession evidence, the no-confession condition was set as the reference group. Because the models provide no omnibus test for effects with more than two levels, they provided only comparisons between (a) the no-confession condition and coerced-confession condition and (b) the no-confession condition and voluntary-confession condition. Supplementary chi-square analyses tested comparisons between the coerced-confession condition and voluntary-confession condition. To test effects of disability status, the nondisabled condition was set as the reference group.

In addition, 3 (confession evidence: no confession, coerced confession, voluntary confession) 
X 2 (disability status: disabled, nondisabled) between-subjects analyses of variance tested effects on each continuous dependent variable. Significant main effects of confession evidence were followed up with planned comparisons.

So that the reader can consider effects across all related dependent variables at once, results are organized by (a) main effects of confession evidence then (b) main effects of disability status. There were no significant interactive effects of confession evidence and disability status, all $b s \leq$ $|1.26|, z s \leq|1.45|, n s$, and all $F s(1-2,125-264) \leq 2.53, n s$. When not specified otherwise, all frequencies, means, and standard deviations are presented in Table 1 and all test statistics and effect sizes are presented in Table 2. Then, we present results from path analyses exploring the ability of proposed mediators to explain the significant effects.

Finally, we present a second set of all these analyses using as a grouping factor not jurors' assigned experimental condition, but instead, whether jurors really perceived the juvenile in line with the manipulations, as detailed below and shown in Tables 1 and 2.

\section{Main Analyses}

\section{Main effects of confession evidence.}

Guilt and suspicion judgments. A log-linear model of the effects of confession evidence and disability status on jurors' dichotomous verdicts revealed that, as predicted, jurors were significantly more likely to convict the juvenile when she confessed voluntarily than when she did not confess (see Figure 1). Conviction rates did not significantly differ for a juvenile who was coerced to confess and a juvenile who never admitted any criminal involvement, however. Thus, jurors discounted the coerced confession, but not completely, because a chi-square analysis revealed that jurors were just as likely to think the juvenile was guilty when she confessed under coercion or voluntarily.

In contrast, when asked whether they suspected guilt regardless of their verdict, jurors were no less likely to suspect guilt when the juvenile did not confess as compared to when she confessed 
under coercion or when she confessed voluntarily. Jurors were, however, significantly less likely to suspect the juvenile when she confessed under coercion versus voluntarily.

Trial venue and sentencing recommendations. Confession evidence did not significantly influence recommendations for trial venue, juvenile court sentences, nor adult court sentences among jurors who voted guilty.

Confession-related judgments. As predicted, jurors' ratings on the perceived suggestibility scale differed significantly as a function of confession evidence. Jurors perceived the juvenile as significantly more suggestible when she confessed under coercion than when she did not confess or when she confessed voluntarily. The latter two conditions did not differ significantly. Sixty percent of jurors perceived the juvenile's confession as true when it was coerced, compared to $76 \%$ when it was voluntary, a nonsignificant difference.

Affective reactions, attributions and perceived responsibility for the crime, and sentencing goals. Confession evidence did not significantly affect jurors' sympathy, attributions (i.e., external attributions, internal attributions, attributions of causal control, nor attributions of causal stability), nor perceptions of responsibility for the crime, nor rehabilitative nor retributive sentencing goals, but it did significantly influence their anger. Jurors were significantly more angry at the juvenile when she confessed voluntarily compared to when she did not confess. There were no significant differences in anger, however, for jurors in either the no-confession or voluntary-confession conditions compared to jurors in the coerced-confession condition.

\section{Main effects of disability status.}

Guilt and suspicion judgments. Log-linear modeling revealed that, contrary to our hypothesis, disability status did not significantly influence jurors' verdicts. Fifty percent of jurors voted guilty when the juvenile was portrayed as disabled, and $54 \%$ voted guilty when she was nondisabled. Similarly, disability status did not significantly affect jurors' suspicions of guilt.

Trial venue and sentencing recommendations. Jurors were significantly less likely to 
recommend that a juvenile be tried in adult court rather than juvenile court when she was described as disabled compared to nondisabled. When jurors who voted guilty were asked what sentence the juvenile should get if tried in juvenile court, they were significantly less likely to recommend prison as opposed to probation or psychological treatment for a disabled juvenile than a nondisabled juvenile. When asked what sentence the juvenile should get if tried in adult court, however, jurors were just as likely to recommend prison as probation regardless of the juvenile's disability status.

Confession-related judgments. Jurors perceived a disabled juvenile as significantly more suggestible than a nondisabled juvenile. Even so, disability status did not significantly affect jurors' perceptions of confession truthfulness: $68 \%$ of jurors perceived a disabled juvenile's confession as true and 69\% perceived a nondisabled juvenile's confession as true.

\section{Affective reactions, attributions and perceived responsibility for the crime, and sentencing}

goals. Jurors were significantly more sympathetic and less angry toward a disabled juvenile than a nondisabled juvenile. Among jurors who suspected that the juvenile was guilty, disability status did not significantly influence jurors' external attributions for the juvenile's crime, attributions of causal stability, nor perceptions of responsibility. Jurors did, however, make significantly fewer internal attributions and attributions of control for the crime when the juvenile was portrayed as disabled rather than nondisabled. Among jurors who voted guilty, disability status did not significantly affect the extent to which sentences were based on jurors' rehabilitative nor retributive sentencing goals.

\section{Mediational analyses.}

To test our mediational hypotheses, we first conducted logistic regression analyses predicting each outcome with the independent variable and the potential mediators. (See Tables 3 and 4 for results.) This strategy allowed us to determine whether each mediator was independent of the other mediators (Kenny, 2008). Variables that did not significantly affect the outcome variable were eliminated from consideration. We then tested the more parsimonious models with observed variables path analyses using a structural equation modeling framework (Amos 7, Arbuckle, 2006). 
In line with Kline's (2004) recommendations, (a) the path analyses included at least 10 cases for each model parameter, (b) multicollinearity was not a problem (all first-order correlations $\leq|.47|$ ), and (c) all mediators were univariate normal (skew ranged from -.49 to .52; kurtosis ranged from .79 to .35$)$. Although use of dichotomous dependent variables in structural equation modeling may inflate fit statistics due to violations of multivariate normality, the dependent variables in the models presented (i.e., for suspicions of guilt, trial venue recommendations, juvenile court sentence recommendations) can be assumed to be normal because skewness ranged from -1.40 to .30 and kurtosis ranged from -1.93 to -.05 (Garson, 2009). Even so, we used the percentile bootstrap method, based on 1,000 samples, which is recommended when data do not fit the assumptions of normality (Garson, 2009). This is also the recommended approach for assessing indirect effects (i.e., mediation) (Shrout \& Bolger, 2002; Taylor, MacKinnon, \& Tein, 2008).

Explaining the effect of confession voluntariness. Based on the results of the logistic regression analyses, we tested whether perceived suggestibility explained the effect of confession voluntariness on jurors' suspicions of guilt (see Table 3). A path analysis of a saturated model (i.e., including all possible direct and indirect effects) revealed that the effect of confession voluntariness on suspicions of guilt was mediated by perceptions of the juvenile's suggestibility. Dropping nonsignificant paths from confession voluntariness to suspicions of guilt (see Figure 2) resulted in a good fit (Kenny, 2008). The indirect effect of confession voluntariness on suspicions of guilt was significant, point estimate $=-.07,95 \%$ CI $[-.14,-.01], p<.05$.

Explaining the effects of disability status. First, because our hypotheses were driven by attribution theory and only jurors who suspected that the juvenile was guilty would have made attributions for the juvenile's criminal behavior, we conducted chi-square analyses to test the effect of disability status on verdicts and trial venue recommendations among only those jurors. Jurors who suspected that the juvenile was guilty were just as likely to convict her when she was disabled as compared to nondisabled $(60 \%$ versus $71 \%), \chi^{2}(1,212)=2.62, n s$, but, as predicted, jurors were 
significantly less likely to recommend that she be tried in adult court when she was disabled compared to nondisabled $(24 \%$ versus $66 \%), \chi^{2}(1,211)=37.64, p<.001, \varphi=-.42$. Next, based on the results of the logistic regression analyses (see Table 4), we tested whether, among jurors who suspected the juvenile, internal attributions and attributions of causal control for the crime as well as sympathy toward the juvenile explained the effect of disability status on trial venue recommendations. We also tested whether, among jurors who voted guilty, sympathy explained the effect of disability status on juvenile court sentence recommendations.

Trial venue recommendations. A test of the saturated path model showed that the effect of disability status on jurors' trial venue recommendations was partially and sequentially mediated by jurors' internal attributions and attributions of control for the cause of the juvenile's crime and feelings of sympathy toward the juvenile. Dropping the nonsignificant paths from disability status and internal attributions to sympathy yielded a good model (see Figure 3a). Disability status had significant indirect effects on jurors' sympathy for the juvenile and trial venue recommendations, point estimate $=.30,95 \%$ CI $[.15, .46]$, and point estimate $=-.11,95 \%$ CI $[-.17,-.06]$, respectively, all ps $<.01$. In addition, attributions of causal control had a significant indirect effect on jurors' trial venue recommendations, point estimate $=.04,95 \% \mathrm{CI}[.01, .07], p<.01$.

Juvenile court sentence recommendations. A test of the saturated path model showed that the effect of disability status on jurors' juvenile court sentence recommendations was partially mediated by jurors' feelings of sympathy toward the juvenile (see Figure 3b). Disability status had a significant indirect effect on jurors' sympathy for the juvenile, point estimate $=-.04,95 \%$ CI $[-.10$, $.01], p<.05$.

\section{Perceived Variables Analyses}

Next, we present results from perceived variables analyses, where participants were grouped by what they perceived the experimental variables to be, a method used in mock trial research by Wiley and Bottoms (2009). That is, we anticipated and found that, even though all jurors in these 
analyses remembered our manipulations correctly (or else we would have dropped them from the study for having missed the manipulation check), some jurors read about a voluntary confession but actually thought it was coerced $(n=13)$, and some read about a coerced confession but actually perceived it as voluntary $(n=34)$. This is consistent with past research (see, e.g., Kassin \& McNall, 1991; Kassin \& Sukel, 1997). Also, some jurors read about a nondisabled juvenile but actually thought she was disabled $(n=5)$, and some read about a disabled juvenile but actually perceived her as nondisabled $(n=18)$. Therefore, we replicated our analyses using as the independent variables (a) perceived rather than manipulated confession voluntariness and (b) perceived rather than manipulated disability status. This alternate analytic strategy yielded 32 to 63 participants in each of the new experimental cells. Chi-square analyses ensured that actual confession voluntariness did not significantly influence the tendency to perceive a disabled juvenile as nondisabled or vice versa, $\chi^{2}(1,184)=1.56, n s$, nor did actual disability status significantly influence the tendency to perceive voluntary confessions as coerced or vice versa, $\chi^{2}(1,184)=1.64, n s$. Otherwise, we conducted similar analyses as discussed above. As would be expected, effects from analyses using perceived variables were, in all but a few cases, in the same predicted direction as those using manipulated variables, but much stronger — even moving from nonsignificant to significant for 15 dependent variables, as summarized next. (All frequencies, means, and standard deviations are presented in Table 1 and test statistics and effect sizes are presented in Table 2.)

The perceived variables analyses revealed new significant effects of perceived confession voluntariness on verdicts, suspicions of guilt, trial venue recommendations, juvenile court sentence recommendations, adult court sentence recommendations, perceived confession truthfulness, sympathy, anger, attributions of causal control, and perceived responsibility. Specifically, jurors were significantly less suspicious of, more sympathetic toward, and attributed less responsibility to a juvenile who did not confess as compared to a juvenile who was perceived to have confessed voluntarily. In addition, jurors were significantly less likely to vote guilty, recommend that a 
juvenile be tried in adult court rather than juvenile court, recommend prison as opposed to other alternatives for a juvenile tried in either juvenile or adult court, and think a juvenile's confession was true when it was perceived to have been coerced rather than voluntary. Jurors also reported being significantly more sympathetic and less angry and attributed significantly less control and responsibility when they thought a juvenile confessed under coercion as compared to voluntarily. Jurors were even significantly less likely to recommend a juvenile court sentence of prison as opposed to probation or psychological treatment and attributed significantly less causal control for the crime when a juvenile was perceived to have confessed under coercion compared to when she did not confess. Thus, when jurors' beliefs about whether a confession was coerced or voluntarily were taken into account rather than just the experimental manipulation of confession voluntariness, jurors were more likely to discount a coerced confession completely.

These analyses also revealed a new significant effect of perceived disability status on jurors' retributive sentencing goals. Specifically, jurors who voted guilty were significantly less likely to render a sentence because they thought the juvenile "deserved" it when they perceived that the juvenile was disabled compared to nondisabled. One previously significant effect of disability status was no longer significant: Jurors did not significantly differ in their feelings of anger towards the juvenile based on whether they thought she was disabled or nondisabled.

Again, there were no significant interactive effects of confession voluntariness and disability status, all $b \mathrm{~s} \leq|1.41|, \mathrm{zs} \leq|1.31|, n s$, and all $F \mathrm{~s}(1-2,125-264) \leq 2.81$, ns.

\section{Mediational analyses.}

Following the same procedures outlined above, we used logistic regression analyses to determine whether each mediator was independent of the other mediators (see Tables 5 and 6 for results), eliminated from consideration variables that did not significantly affect the outcome variables, and then tested the more parsimonious models with observed variables path analyses using the percentile bootstrap method. The path analyses included at least 10 cases for each model 
parameter, multicollinearity was not a problem (all first-order correlations $\leq|.68|$ ), and confession truthfulness and verdicts (the only mediator and dependent variable not previously examined) were univariate normal (skew $=-.80$ and -.08 , kurtosis $=-1.37$ and -2.01 , respectively).

Explaining the effects of perceived confession voluntariness. The logistic regression analyses revealed that the effect of perceived confession voluntariness on juvenile court and adult court sentence recommendations was not mediated by variables assessed herein (see Table 5). Thus, we tested whether (a) perceived confession truthfulness, sympathy, and anger explained the effect of perceived confession voluntariness on suspicions of guilt; (b) perceived suggestibility, perceived confession truthfulness, and anger explained the effect of confession voluntariness on verdicts; and (c) perceived confession truthfulness and anger explained the effect of perceived confession voluntariness on trial venue recommendations.

Suspicions of guilt. The saturated path model showed that the effect of perceived confession voluntariness on jurors' suspicions of guilt was sequentially mediated by perceived confession truthfulness and anger, but not sympathy. Removing the sympathy scale and related paths (i.e., from perceived confession voluntariness and confession truthfulness to sympathy, between sympathy and anger, and from sympathy to suspicion of guilt), as well as nonsignificant paths from perceived confession voluntariness to anger and suspicions of guilt resulted in a good fit (see Figure 4a). Perceived confession voluntariness had a significant indirect effect on jurors' anger and suspicions of guilt, all point estimates $\leq-.26,95 \% \mathrm{CI}[-.60,-.22]$ and $[-.36,-.17]$, respectively, $p \mathrm{~s}<.01$. Confession truthfulness also had a significant indirect effect on jurors' suspicions of guilt, point estimate $=.04,95 \%$ CI $[.01, .06], p<.01$.

Verdicts. The saturated path model revealed that the effect of perceived confession voluntariness on jurors' verdicts was mediated sequentially by perceptions of the juvenile's suggestibility and confession truthfulness as well as anger toward the juvenile. Dropping nonsignificant paths from perceived confession voluntariness to anger and verdicts and from 
confession truthfulness to anger resulted in a good fit (Kenny, 2008) (see Figure 4b). The indirect effect of perceived confession voluntariness on verdicts was significant, point estimate $=-.30,95 \%$ CI $[-.39,-.21], p=.001$. The indirect effects of perceived confession voluntariness on jurors' perceptions of confession truthfulness and anger toward the juvenile were also significant, all point estimates $\leq-.25,95 \% \mathrm{CI}[-.32,-.18]$ and $[-.62,-.24]$, respectively, $p s=.001$. The indirect effect of perceived suggestibility on jurors' verdicts was also significant, point estimate $=-.15,95 \%$ CI $[-.21$, $-.09], p=.001$.

Trial venue recommendations. A saturated path analysis revealed that the effect of perceived confession voluntariness on jurors' trial venue recommendations was mediated by jurors' sympathy for the juvenile. Dropping the nonsignificant path from perceived confession voluntariness to trial venue recommendations resulted in a poor fit (see Figure 4c). Still, perceived confession voluntariness had a significant indirect effect on jurors' trial venue recommendations, point estimate $=-.08,95 \% \mathrm{CI}[-.15,-.03], p<.01$.

Explaining the effects of perceived disability status. First, we conducted chi-square analyses to test the effect of perceived disability status on verdicts and trial venue recommendations among only jurors who suspected that the juvenile was guilty. As predicted, jurors who suspected that the juvenile was guilty were significantly less likely to convict her (58\% versus $71 \%)$ and significantly less likely to recommend that she be tried in adult court (21\% versus $64 \%)$ when they thought she was disabled compared to nondisabled, all $\chi^{2} \mathrm{~s}(1,211-212) \geq 3.88, p s \leq .05, \varphi s \leq-.14$. Next, the logistic regression analyses revealed that the effect of perceived disability status on juvenile court sentence recommendations was not significantly mediated by variables assessed herein (see Table 6). Thus, we tested whether, among jurors who suspected the juvenile, (a) internal attributions for the crime explained the effect of perceived disability status on verdicts and (b) attributions of causal control for the crime and sympathy toward the juvenile explained the effect of perceived disability status on trial venue recommendations. 
Verdicts. A saturated path analysis confirmed that jurors' internal attributions for the cause of the juvenile's crime mediated the effect of perceived disability status on jurors' verdicts. Dropping the nonsignificant path from disability status to verdicts yielded an adequate model (see Figure 5a). Perceived disability status had a significant indirect effect on verdicts, point estimate $=$ $.04,95 \%$ CI $[-.08,-.00], p<.05$.

Trial venue recommendations. A test of the saturated path model showed that the effect of perceived disability status on jurors' trial venue recommendations was partially mediated by jurors' attributions of control for the cause of the juvenile's crime and feelings of sympathy toward the juvenile. Dropping the nonsignificant path from perceived disability status to sympathy yielded an adequate model (see Figure 5b). Perceived disability status had significant indirect effects on jurors' sympathy for the juvenile and trial venue recommendations, point estimate $=.36,95 \% \mathrm{CI}[.20, .52]$, and point estimate $=-.09,95 \%$ CI $[-.16,-.04]$, respectively, all $p s<.01$. In addition, attributions of causal control had a significant indirect effect on jurors' trial venue recommendations, point estimate $=.04,95 \%$ CI $[.01, .07], p<.01$.

\section{Discussion}

As we predicted, our results revealed that mock jurors are sensitive to the social psychological circumstances of juveniles' confessions. Yet, the extent of this sensitivity depended on whether we analyzed results as a function of how the confession was actually described in the materials or how jurors perceived it. Our primary analyses, based on our manipulation of confession evidence, revealed that jurors' judgments were often unaffected by a juvenile defendant's confession, regardless of whether it was coerced or voluntary. In fact, the only significant difference we found between the coerced-confession and no-confession conditions was that jurors rated a juvenile as more suggestible when she confessed under coercion than when she never admitted any criminal involvement. Still, even though jurors were frequently not biased by the coerced confession, they did not discount it completely because there were only two significant differences 
between the coerced-confession and voluntary-confession conditions: A juvenile was rated as less suggestible and less likely to be suspected as guilty when her confession was described as coerced rather than voluntary. Thus, jurors often made similar judgments for a juvenile who was coerced to confess and a juvenile who confessed voluntarily, including anger ratings and verdicts, the only two dependent measures on which jurors were more punitive for a juvenile who confessed voluntarily than a juvenile who never confessed.

When we conducted analyses as a function of jurors' true perceptions about the juvenile's confession, however, most of these effects remained significant and 14 other significant differences emerged, all of which were consistent with our hypotheses. Specifically, as predicted, in addition to being more angry and more likely to vote guilty, jurors were also more likely to suspect the juvenile was guilty and to rate her as less suggestible and more responsible for the crime when they thought she confessed voluntarily as compared to when she never confessed. Also, jurors generally made similar judgments for a juvenile whom they thought confessed under coercion and a juvenile who did not confess, except that they made more favorable juvenile court sentence recommendations, suggestibility ratings, and attributions of causal control when the juvenile was perceived to have confessed under coercion. Further, across 11 of 16 dependent measures (excluding attributions related to internal locus, external locus, and stability and rehabilitative and retributive sentencing goals), jurors made more favorable judgments for a juvenile when they perceived her confession as having been coerced versus given voluntarily, as hypothesized. Thus, across a variety of measures, jurors completely discounted a confession that they perceived as coerced. Next, we review these findings in the context of prior theory and research.

Considering the results of the perceived analyses, as expected, jurors were more likely to suspect and convict a juvenile when they perceived her confession to be voluntary rather than coerced, but no more likely to suspect or convict a juvenile who confessed under coercion compared to a juvenile who did not confess. Jurors were even less suspicious that a juvenile was 
guilty when they thought she confessed under coercion than when she did not confess. Jurors also fully discounted a juvenile's coerced confession when making trial venue and sentencing recommendations. Considering our results in light of other research documenting jurors' overreliance on adults' coerced confessions (e.g., Kassin \& McNall, 1991), it is possible that jurors might recognize the increased vulnerability of juvenile compared to adult suspects. Future research should test this possibility directly.

Consistent with prior research (e.g., Najdowski et al., 2009; Redlich, Quas, \& Ghetti, 2008), jurors appear to realize the link between juveniles' suggestibility and false confessions, as supported by the finding that jurors rated the girl as more suggestible in the coerced-confession condition than in the no-confession condition. Also, in line with research on perceptions of child witnesses and defendants (e.g., Castelli et al., 2005; Najdowski et al., 2009; Redlich, Quas, \& Ghetti, 2008), jurors recognized the potential for police interrogation tactics to influence the truthfulness of a confession: The perceived-confession analyses revealed that jurors were less likely to think that the juvenile confessed because she was actually guilty when she confessed under coercion compared to voluntarily. Jurors also discounted coerced confessions in terms of affective reactions: They were more sympathetic and less angry toward a juvenile when she confessed under coercion compared to voluntarily. These findings fit nicely with attribution theory, and path analyses provided support for our mediational hypotheses. For example, jurors perceived a juvenile as more suggestible when they thought she confessed under coercion rather than voluntarily, which in turn decreased jurors' beliefs that her confession was true and made jurors less angry, and reduced the likelihood that jurors would vote guilty. Perceiving the confession as untrue and feeling less angry also reduced jurors' tendency to suspect that the juvenile was guilty of murder, regardless of how they actually voted. Finally, jurors who perceived that a confession was coerced rather than voluntary felt more sympathy for the juvenile, which in turn decreased jurors' tendency to recommend that the juvenile be tried in adult rather than juvenile court. Thus, not only were we able to show that jurors discount 
juveniles' coerced confessions, but we also discovered why: Coerced confessions highlight juveniles' suggestibility, which, consistent with the discounting principle (Kelley, 1973; Kelley \& Michela, 1980), counters jurors' natural tendency to believe that people confess because they are actually guilty. That is, jurors who realize that a juvenile is suggestible are more likely to recognize the coercive circumstances as a plausible cause of the confession. We theorized that believing that a confession was true would be analogous to an internal attribution for the confession, but future research might use more direct measures to assess jurors' internal and external attributions for confessions.

Although jurors recommended more lenient sentences for juveniles who were perceived as having confessed under coercion versus voluntarily, this effect was not explained by jurors' perceptions of the juvenile's suggestibility nor confession truthfulness nor their affective reactions. This might be because only jurors who voted guilty rendered sentencing judgments, and that subsample of jurors had reduced variance on measures of perceived suggestibility and perceived confession truthfulness relative to all jurors in the confession conditions. Alternatively, Woody and Forrest (2009) showed that, even though mock jurors convicted an adult defendant just as frequently when she confessed under coercive conditions or voluntarily, they recommended shorter sentences for an adult who confessed under coercion. Thus, sentencing decisions might be driven by factors we did not measure which are relevant for both juvenile and adult defendants. Future research might explore this possibility while also improving upon our measures. For example, it might be clearer to ask participants about their recommendations for the "most appropriate" rather than "best" outcome or punishment for the juvenile, and measures should also capture the possibility that participants might believe multiple outcomes are best (i.e., psychological treatment and imprisonment).

Surprisingly, perceived confession voluntariness also influenced jurors' attributions of causal control and perceptions of responsibility for the juvenile's criminal behavior. Specifically, jurors thought that the juvenile had less control over her criminal behavior when they believed she 
had confessed under coercion compared to voluntarily. Although we did not predict this finding and it is not intuitively logical, it is possible that jurors' attributions about the cause of the juvenile's confession influenced their attributions related to the cause of her criminal behavior. Jurors might think that, compared to a defendant who confessed voluntarily, a defendant who was coerced to confess had less control not only over her decision to confess (i.e., because she is suggestible) but also over other aspects of her behavior. It has been recognized that confession evidence taints jurors' perceptions of other case elements in the direction of confirming a defendant's guilt (see Kassin et al., 2010), but the results of the present study suggest that jurors who believe that a defendant falsely confessed might be immune to such effects and might even be likely to see other evidence in a more favorable light. Future research should explore how and why jurors' attributions for the causes of defendants' confessions affect their reactions to other case factors.

Counter to Najdowski et al.’s (2009) results, jurors discounted a perceived-coerced confession regardless of whether the juvenile was disabled or nondisabled, even though they thought a disabled juvenile was more suggestible, as found by Najdowski et al. Perhaps the use of more realistic materials (i.e., more elaborate written case scenarios, videotaped testimony, actual jury instructions) in this study was sufficient to make the juvenile defendant's suggestibility salient to jurors. Future research might test this directly by varying mode of testimony presentation (i.e., written versus video) or whether jury instructions are used within the same study.

Indeed, we expected the use of more ecologically valid materials in this study to have made the disability status manipulation more salient to jurors than in Najdowski et al.'s (2009) Study 2, in which jurors were exposed to only brief written scenarios and judged a disabled juvenile as less guilty and less responsible only when she was accused of a fairly non-serious offense (i.e., a drug offense), as opposed to more serious offenses (i.e., assault, murder). Consistent with this finding but contrary to our prediction, jurors in the present study did not take a juvenile's disability into account when formulating their suspicions or rendering their verdicts. We suggested that jurors might find it 
implausible that a juvenile is truly disabled when she is on trial in adult court for a serious crime involving vicious intent, which presumably requires some degree of competence and/or cognitive and criminal sophistication. This contention does not explain the null effect of disability status, however, because it manifested when we tested the effects of both the juvenile defendant's actual disability status and jurors' beliefs about whether she was disabled. Thus, in contrast to Gibbons et al.'s (1981) finding that mock jurors believed it was less likely that a disabled than nondisabled adult committed burglary and assault, perhaps jurors simply do not distinguish between disabled and nondisabled juveniles when deciding how likely it is that they committed a serious crime like murder. Alternatively, it is possible that jurors' suspicions and verdicts were not influenced by disability status because the alleged crime described in our study was not a very complex one (i.e., the victim was drunk and unable to defend himself, the juvenile lived with the victim and had easy access to him). Future research might examine whether a juvenile's disability status influences jurors' judgments in cases involving more complicated crimes, which presumably require greater cognitive abilities to perpetrate.

It is also possible that disability status did not have had a major impact on jurors' decision making in this study because participants' stereotypes about intellectual disability might have been challenged. Research has demonstrated that jurors have expectancies about how adult defendants and child witnesses should behave, and when those expectations are violated, they perceive defendants and witnesses as less believable and render less favorable judgments (for reviews, see Heath, 2009; McAuliff \& Kovera, 2002). Consider the case of Barry Laughman, a disabled adult who had falsely confessed: Although jurors were originally inclined to acquit, they reported that Laughman's “seemingly normal appearance” led them to convict (Warden \& Drizin, 2009, p. 229). This could be particularly problematic in cases involving juveniles who are only mildly disabled, in which jurors' expectancies about intellectual disability might be especially likely to be violated.

Still, what happens when jurors come face-to-face with an intellectually disabled juvenile in 
an actual trial remains to be seen. Jurors might render less favorable judgments for disabled than nondisabled juveniles because they might appear unremorseful or uninterested simply because they do not comprehend what is happening. In contrast, disability might be used as a mitigating factor in actual cases, where jurors might think that punishment is not as appropriate for disabled compared to nondisabled juveniles. In support, our research revealed that jurors were less likely to recommend that a juvenile be tried as an adult when she was disabled compared to when she was nondisabled. Jurors also recommended more lenient sentences (i.e., probation or psychological treatment rather than imprisonment) for a disabled juvenile than a nondisabled juvenile tried in juvenile court (but not in adult court). Although these effects were true regardless of whether the juvenile was actually disabled or jurors only thought she was, jurors who suspected that the juvenile was guilty were less likely to convict her only when they perceived her as disabled compared to nondisabled. Thus, jurors might think that disabled juveniles are less worthy of conviction for crimes committed compared to nondisabled juveniles. Future research might test whether jurors are inclined to nullify the law by acquitting disabled juveniles even when they are convinced of guilt beyond a reasonable doubt.

This research illuminated some of the psychological processes by which disability status affects jurors' decision making in cases involving juvenile defendants. Contrary to prior research (Gibbons et al., 1981; Najdowski et al., 2009), jurors who had suspicions of guilt were not more likely to think that a disabled compared to nondisabled juvenile committed murder because of external situational factors, was less likely to commit future crimes, or was less responsible for her criminal behavior. Consistent with the patronization effect (Gibbons et al., 1981), discounting principle (Kelley, 1973), and our hypotheses, however, jurors were less likely to think that a disabled compared to nondisabled juvenile committed the crime because she had a criminal character or deviant nature (see also Najdowski et al., 2009) and had control over her criminal behavior. Jurors were also more sympathetic and less angry toward a disabled compared to 
nondisabled juvenile, although the differences in anger became nonsignificant when analyzed as a function of perceived disability status. And, although jurors' rehabilitative and retributive sentencing goals were not influenced by a juvenile's actual disability status, jurors were less likely to sentence a juvenile who seemed disabled because they thought she deserved it.

In line with attribution theory, these differential attributions and affective reactions were useful in understanding the effect of intellectual disability on jurors' case judgments. First, we considered the effects of the juvenile's actual disability status. Jurors were less likely to recommend that a disabled compared to nondisabled juvenile be tried in adult court in part because they thought a disabled juvenile was less deviant and had less control over her criminal behavior, which in turn increased sympathy for the juvenile. Increased sympathy also partially explained why jurors rendered more lenient juvenile court sentences for a disabled than a nondisabled juvenile. Second, we examined the influence of jurors' beliefs about the juvenile's disability status, regardless of what the manipulation stated. These results indicated that sympathy did not explain differences in jurors' juvenile court sentences for a juvenile who seemed disabled compared to nondisabled. Also, although internal attributions for the cause of the juvenile's criminal behavior did not contribute to the effect of perceived disability status on jurors' trial venue recommendations, among jurors who suspected that the juvenile was guilty, jurors were less likely to convict a juvenile who they perceived as disabled rather than nondisabled specifically because they were less likely to think a disabled juvenile had an inherently criminal character or deviant nature.

These results provide some support for our hypotheses and are consistent with other research that has applied attribution theory to justice-related decisions (e.g., Graham et al., 1997), although jurors' attributions of causal locus and controllability and affective reactions of sympathy appear to be more important for understanding judgments for disabled juvenile defendants than are jurors' attributions regarding stability or culpability, feelings of anger, or sentencing goals. Our predictions were based on Weiner's (2006) conceptualization of attribution theory, but in other work Weiner 
and colleagues (e.g., Graham et al., 1997; Weiner et al., 1997) have argued that controllability and stability are more relevant than locus for understanding punishment-related decisions. Attributions of locus were the only type of attribution that influenced jurors' decisions about whether they should convict a juvenile that they suspected was guilty, however. Further, attributions of controllability played an important role in affecting jurors' judgments about the appropriate trial venue for a juvenile defendant, but attributions of stability did not explain jurors' verdicts nor trial venue recommendations. Thus, attributions of causal locus are indeed relevant for understanding punishment-related decisions, at least for juvenile defendants. Our results suggest that it might be important to elaborate existing models to gain a fuller appreciation of the process by which jurors render judgments. For example, attributions of causal intent (i.e., the extent to which a person purposefully causes an outcome; see Weiner, 1985) are probably relevant for explaining judgments related to a defendant's criminal behavior and jurors' attributions might influence other affective reactions (e.g., empathy, moral outrage) not accounted for in current models. Further, neither the causal attributions we assessed, perceptions of responsibility, nor sentencing goals were relevant for understanding jurors' recommendations for sentencing the juvenile, so the tendency to render more lenient juvenile court sentences for a disabled compared to nondisabled juvenile is probably explained by other psychological mechanisms not measured herein (e.g., beliefs about availability of special services for disabled juveniles in prison).

\section{Methodological Strengths and Limitations}

Our study was ecologically valid in many respects. Participants were over 18 years old, United States citizens, and ethnically diverse, as actual jurors would be. Our case details were drawn from an actual case and included appropriate charges, legally admissible evidence, and ecologically valid variables manipulated in realistic ways. For example, the incorporation of footage from an actual trial, as recommended by Bornstein (1999), increased the realism of this study relative to other mock trial research using only written materials (e.g., Najdowski et al., 2009) by 
allowing jurors to have a realistic image of the defendant to think about while making their case judgments. Also, we impressed upon jurors the seriousness of the research, confirming by observation that they were engaged in the task. Jurors received the jury instructions actually used in our state, and we asked jurors for the same determination of guilt that real jurors would make.

Even so, caution is warranted in generalizing from our results to actual cases because even the best simulations fail to replicate some aspects of real trials (Diamond, 1997; Weiten \& Diamond, 1979). Our mock jurors were not exposed to a lengthy trial, and were students rather than older, more representative community members. Although one might argue that sample could make a difference in cases involving defendants so near in age to the mock jurors, undergraduates and community members had similar perceptions of a girl defendant in a study by Haegerich and Bottoms (2004; see also Bornstein, 1999; Lassiter, 2002; Salerno et al., 2010). Even so, replication with a community sample is an important next step to take. Also, our mock jurors did not deliberate as a group, which might attenuate (Shaw \& Skolnick, 1995) or amplify (Moscovici \& Zavalloni, 1969 ) individual jurors' biases. Yet several studies (including Haegerich \& Bottoms', 2004, study involving a similar juvenile defendant) have found that deliberation has few effects on postdeliberation verdicts as compared to the average of pre-deliberation verdict preferences (Kalven $\&$ Zeisel, 1966; MacCoun \& Kerr, 1988; Sandys \& Dillehay, 1995).

Because some of our mock jurors did not think of the defendant as described by the manipulation, in our analyses, we grouped participants first as defined by our manipulated independent variables, then by what participants really believed to be true about the juvenile's confession and disability status. This does not mean that our manipulations were unsuccessful: All participants retained in both sets of analyses noted the confession and disability manipulations correctly; they simply did not believe them — as they are free to do in an actual trial. This is likely to be the case in many studies, yet experimenters are unaware of it because they ask only the usual manipulation check questions without going further to ask their participants what they believe 
regardless of the manipulation. Our decision to present both analyses is not unprecedented. Wiley and Bottoms (2009) used a similar strategy to explore how jurors' judgments in a child sexual abuse trial were influenced by a defendant's sexual orientation. The results of our secondary perceivedvariables analyses are in the same direction as the other analyses, but amplified, which is consistent with what Wiley and Bottoms (2009) found and precisely what one would expect if the strength of the effects uncovered by the original analyses were "watered down" by the fact that the experimental groups contained participants who chose to interpret our manipulation differently than intended. Further, the results of our perceived variables analyses were not only more consistent with our theories and hypotheses than were the results of the original analyses, they were also more consistent with prior research findings. For instance, jurors were more consistently punitive when rendering judgments for a juvenile when they perceived that she confessed voluntarily compared to when she never confessed, which is logical and consistent with other studies of jurors' perceptions of adults' confessions (e.g., Kassin \& Sukel, 1997).

Although we think it is unlikely, one could argue that causal conclusions based on the analyses of perceived versus manipulated variables are limited, because participants' initial judgments might have affected how they later perceived the confession. To remedy this, future research could probe how jurors actually perceive experimental manipulations before and after they make judgments. Even so, our methodology is still an improvement on studies that do not take such perceptions into account at all. Our research makes an important contribution to the literature by showing that jurors do not always believe what they are told and that their beliefs are a stronger predictor of their judgments than are the actual case facts.

\section{Implications for Public Policy and Law}

In addition to theoretical significance, our results have practical implications for public policy and law. The issues we studied are realistic and of applied importance. For example, jurors' judgments for a mildly intellectually disabled girl who falsely confessed to murder are worthy of 
study for at least four reasons. First, severely disabled defendants are typically identified and diverted to alternative programs, but those with mild disabilities might not be detected or, consequently, receive any legal protection (see Perlin, 2003). Second, boys are more likely to offend than girls, but the number of girl offenders is rising faster than boys and they deserve empirical attention (Garbarino, 2006). Third, many cases of proven false confessions involve wrongful accusations of murder (see, e.g., Drizin \& Leo, 2004; Gross, 2008), probably because police use more coercive interrogation strategies when trying to elicit confessions for more serious crimes (see Gudjonsson, 2003). Finally, we described an interrogation involving coercive techniques (i.e., minimization, false evidence ploy) which are used commonly and known to increase the likelihood of false confessions (see Kassin et al., 2010, for review).

Understanding how jurors reach judgments in cases involving juveniles is useful information for attorneys, who might try to influence case outcomes by manipulating jurors' attributions and affective reactions via the evidence or testimony they introduce or with explicit appeals to jurors made during opening and closing statements (see, e.g., Haegerich \& Bottoms, 2000). For example, defense attorneys could capitalize on jurors' attributional and affective tendencies by arguing that disabled juveniles are not inherently deviant and have little control over their behavior. Future research could test the effectiveness of such attorney tactics directly.

In addition, attorneys' statements, judicial instructions, and/or expert testimony designed to educate jurors about the link between disability and delinquency might help jurors think of disability as a mitigating factor when judging juvenile defendants' culpability. Yet, there is some concern that such efforts might backfire: In Atkins v. Virginia (2002), the United States Supreme Court warned that testimony about mental retardation might be misused by jurors as evidence of future dangerousness (see Perlin, 2003, for review). Although intellectual disability was not associated with more punitive judgments nor more attributions of causal stability in this study, some support for this concern comes from Levine et al.'s (2001) finding that more than a third of mock 
jurors said that an 11-year-old juvenile's learning disability would influence them to vote guilty. Thus, more research is necessary to understand the conditions that determine whether intellectual disability is used in favor of juveniles or against them.

Another example of a procedural safeguard that could be implemented to ensure fair trials for juveniles in adult court is expert testimony about juveniles' susceptibility to interrogative pressure. Such testimony might diminish the contaminating effect of confessions on jurors' judgments. Although our results suggest that some jurors are already sensitive to these concerns with juvenile defendants who confess under coercion, not all jurors were (see also Chojnacki et al., 2008; Henkel et al., 2008). For example, despite knowing that a confession was elicited after many hours of stressful interrogation involving deceitful tactics, some jurors still perceived a coerced confession to be voluntary. Woody and Forrest (2009) showed that expert testimony can be used to educate jurors about the link between false confessions and coercive interrogation tactics like those presented in this study. Perhaps testimony focused on juveniles' heightened suggestibility and susceptibility to coercion, particularly among disabled juveniles, might be effective at communicating the need for jurors to consider juveniles' confessions carefully. Making suggestibility salient might even be useful for making jurors evaluate the circumstances of adults' coerced confessions more carefully. Future research should consider these possibilities.

Our results also suggest that a substantial minority of the public does not support the application of transfer policies to all juveniles, consistent with prior research (e.g., Nunez et al., 2007; Reppucci, Scott, \& Antonishak, 2009; Stalans \& Henry, 1994), particularly those who are disabled. This has interesting implications for juvenile transfer policies, because few states take intellectual disability into account when determining whether a juvenile should be transferred (Griffin, Torbet, \& Szymanski, 1998). That is, the movement for juveniles to be tried in adult court might be due in part to policymakers' perceptions of public support for such "get tough" policies, but our findings suggest that jurors' beliefs might be less consistent with policies advocating harsh 
punishment for juvenile offenders than with psychological research showing that diminished capacities increase the likelihood of delinquent behavior (Steinberg \& Scott, 2003) and legal decisions that such diminished capacities reduce juvenile and disabled defendants' culpability for crimes committed (Atkins v. Virginia, 2002; Roper v. Simmons, 2005).

Finally, research should also seek to understand how family and juvenile court judges react to juveniles. Other legal players' (e.g., correctional or probation officers) perceptions of juveniles who have confessed and disabled juveniles should also be studied to gain an understanding of how such juveniles are perceived after adjudication or conviction. All of these issues present opportunities for future research to understand jurors' judgments in cases involving juvenile defendants. Such increased understanding has the potential to lead to change, change that can help ensure fairness for some of the most vulnerable defendants in our legal system. 


\section{References}

American Lawyer/Court TV Video Library Service (1991). Kentucky v. English trial story [motion picture]. Available from Courtroom Television Network, 600 Third Avenue, New York, NY 10016. Arbuckle, J. L. (2006). AMOS (Version 7) [Computer Software]. Chicago: Small Waters. Atkins v. Virginia, 536 U.S. 304 (2002).

Bornstein, B. H. (1999). The ecological validity of jury simulations: Is the jury still out? Law and Human Behavior, 23, 75-91. doi: 10.1023/A:1022326807441

Bottoms, B. L., Nysse-Carris, K. L., Harris, T., \& Tyda, K. (2003). Jurors' perceptions of adolescent sexual assault victims who have intellectual disabilities. Law and Human Behavior, 27, 205-227. doi: $10.1023 / \mathrm{A}: 1022551314668$

Castelli, P., Goodman, G. S., \& Ghetti, S. (2005). Effects of interview style and witness age on perceptions of children's credibility in sexual abuse cases. Journal of Applied Social Psychology, 35 , 297-319. doi: 10.1111/j.1559-1816.2005.tb02122.x

Chojnacki, D. E., Cicchini, M. D., \& White, L. T. (2008). An empirical basis for the admission of expert testimony on false confessions. Arizona State Law Journal, 40, 1-45.

Darley, J. M., Carlsmith, K. M., \& Robinson, P. H. (2000). Incapacitation and just deserts as motives for punishment. Law and Human Behavior, 24, 659-683. doi: 10.1023/A:1005552203727

Diamond, S. S. (1997). Illuminations and shadows from jury simulations. Law and Human Behavior, 21, 561-571. doi: 10.1023/A:1024831908377

Drizin, S. A., \& Colgan, B. A. (2004). Tales from the juvenile confession front: A guide to how standard police interrogation tactics can produce coerced and false confessions from juvenile suspects. In G. D. Lassiter (Ed.), Interrogations, confessions, and entrapment (pp. 127-162). New York: Kluwer Academic.

Drizin, S. A., \& Leo, R. A. (2004). The problem of false confessions in the post-DNA world. North Carolina Law Review, 82, 891-1007. 
Garbarino, J. (2006). See Jane hit: Why girls are growing more violent and what we can do about it. New York: Penguin Press.

Garson, G. D. (2009). Structural equation modeling. Retrieved May 15, 2009, from http://faculty.chass.ncsu.edu/garson/PA765/structur.htm

Garvey, S. P. (1998). Aggravation and mitigation in capital cases: What do jurors think? Columbia Law Review, 98, 1538-1576.

Gibbons, F. X., Gibbons, B. N., \& Kassin, S. M. (1981). Reactions to the criminal behavior of intellectually disabled and nondisabled offenders. American Journal of Mental Deficiency, 86, 235 242.

Gibbons, F. X., Sawin, L. L. C., \& Gibbons, B. N. (1979). Evaluations of mentally retarded persons: Sympathy or patronization? American Journal of Mental Deficiency, 84, 124-131.

Goldstein, N. E. S., Condie, L. O., Kalbeitzer, R., Osman, D., \& Geier, J. L. (2003). Juvenile offenders' Miranda rights comprehension and self-reported likelihood of offering false confession. Assessment, 10, 359-369. doi: 10.1177/1073191103259535

Graham, S., Weiner, B., \& Zucker, G. S. (1997). An attributional analysis of punishment goals and public reactions to O. J. Simpson. Personality and Social Psychology Bulletin, 23, 331-346. doi: $10.1177 / 0146167297234001$

Griffin, P., Torbet, P., \& Szymanski, L. (1998). Trying juveniles as adults in criminal court: An analysis of state transfer provisions. Washington, DC: U.S. Department of Justice.

Gross, S. R. (2008). Judging innocence. Columbia Law Review, 108, 55-142.

Gudjonsson, G. H. (2003). The psychology of interrogations and confessions: A handbook. West Sussex, England: Wiley.

Haegerich, T. M., \& Bottoms, B. L. (2000). Empathy and jurors' decisions in patricide trials involving child sexual assault allegations. Law and Human Behavior, 24, 421-448. doi: 
Haegerich, T. M., \& Bottoms, B.L. (2004, March). Effect of jurors'stereotypes of juvenile offenders on pre- and post-deliberation case judgments. Paper presentation at the annual meeting of the American Psychology-Law Society, Scottsdale, Arizona.

Heath, W. P. (2009). Arresting and convicting the innocent: The potential role of an "inappropriate" emotional display in the accused. Behavioral Sciences and the Law, 27, 313-332. doi: $10.1002 / \mathrm{bsl} .864$

Henkel, L. A., Coffman, K. A. J., \& Dailey, E. M. (2008). A survey of people's attitudes and beliefs about false confessions. Behavioral Sciences and the Law, 26, 555-584. doi: 10.1002/bs1.826

In re L. M., No. 96,197 (Kan. June 20, 2008).

Kalven, H., Jr., \& Zeisel, H. (1966). The American jury. Boston: Little, Brown, and Company. Kasimar, Y., LaFave, W., \& Israel, J. (1994). Modern criminal procedure (8th ed.). St. Paul, MN: West. Kassin, S. M. (1997). The psychology of confession evidence. American Psychologist, 52, 221-233. doi: 10.1037/0003-066X.52.3.221

Kassin, S. M., Drizin, S. A., Grisso, T., Gudjonsson, G. H., Leo, R. A., \& Redlich, A. D. (2010). Policeinduced confessions: Risk factors and recommendations. Law and Human Behavior, 34, 3-38. doi: $10.1007 / \mathrm{s} 10979-009-9188-6$

Kassin, S. M., \& Gudjonsson, G. H. (2004). The psychology of confessions: A review of the literature and issues. Psychological Science in the Public Interest, 5, 33-67. doi: 10.1111/j.15291006.2004.00016.x

Kassin, S. M., \& McNall, K. (1991). Police interrogations and confessions: Communicating promises and threats by pragmatic implication. Law and Human Behavior, 15, 233-251. doi: 10.1007/BF01061711

Kassin, S. M., Meissner, C. A., \& Norwick, R. J. (2005). "I'd know a false confession if I saw one": A comparative study of college students and police investigators. Law and Human Behavior, 29, 211 227. doi: 10.1007/s10979-005-2416-9

Kassin, S. M., \& Sukel, H. (1997). Coerced confessions and the jury: An experimental test of the 
“harmless error" rule. Law and Human Behavior, 21, 27-46. doi: 10.1023/A:1024814009769

Kassin, S. M., \& Wrightsman, L. S. (1980). Prior confessions and mock juror verdicts. Journal of Applied Social Psychology, 10, 133-146. doi: 10.1111/j.1559-1816.1980.tb00698.x

Kassin, S. M., \& Wrightsman, L. S. (1981). Coerced confessions, judicial instruction, and mock juror verdicts. Journal of Applied Social Psychology, 10, 133-146. doi: 10.1111/j.15591816.1981.tb00838.x

Kazdin, A. E. (2000). Adolescent development, mental disorders, and decision making of delinquent youths. In T. Grisso \& R. G. Schwartz (Eds.), Youth on trial: A developmental perspective on juvenile justice (pp. 33-65). Chicago: The University of Chicago Press.

Kelley, H. H. (1973). The processes of causal attribution. American Psychologist, 28, 107-128. doi: $10.1037 / \mathrm{h} 0034225$

Kelley, H. H., \& Michela, J. L. (1980). Attribution theory and research. Annual Review of Psychology, 31, 457-501. doi: 10.1146/annurev.ps.31.020180.002325

Kenny, D. A. (2008). Homepage of David A. Kenny. Retrieved March 17, 2009, from http://davidakenny.net.

Kline, R. B. (2004). Principles and practice of structural equation modeling (2nd ed.). New York: Guilford.

Laimon, R. L., \& Poole, D. A. (2008). Adults usually believe young children: The influence of eliciting questions and suggestibility presentations on perceptions of children's disclosures. Law and Human Behavior, 32, 489-501. doi: 10.1007/s10979-008-9127-y

Lassiter, G. D. (2002). Illusory causation in the courtroom. Current Directions in Psychological Science, 11, 204-208. doi: 10.1111/1467-8721.00201

Lego v. Twomy, 404 U.S. 477 (1972).

Leo, R. A., \& Liu, B. (2009). What do potential jurors know about police interrogation techniques and false confessions? Behavioral Sciences and the Law, 27, 381-399. doi: 10.1002/bsl.872 
Leo, R. A., \& Ofshe, R. J. (1998). The consequences of false confessions: Deprivations of liberty and miscarriages of justice in the age of psychological interrogation. Journal of Criminal Law and Criminology, 88, 429-496.

Levine, M., Williams, A., Sixt, A., \& Valenti, R. (2001). Is it inherently prejudicial to try a juvenile as an adult? Behavioral Sciences and the Law, 19, 23-31. doi: 10.1002/bs1.428

MacCoun, R. J., \& Kerr, N. L. (1988). Asymmetric influence in mock jury deliberation: Jurors' bias for leniency. Journal of Personality and Social Psychology, 54, 21-33. doi: 10.1037/0022-3514.54.1.21

McAuliff, B. D., \& Kovera, M. B. (2002). The status of evidentiary and procedural innovations in child abuse proceedings. In B. L. Bottoms, M. B. Kovera, \& B. D. McAuliff, Children, social science, and the law (pp. 412-445). Cambridge, UK: Cambridge University Press.

Moscovici, S., \& Zavalloni, M. (1969). The group as a polarizer of attitudes. Journal of Personality and Social Psychology, 12, 125-135. doi: 10.1037/h0027568

Najdowski, C. J., Bottoms, B. L., \& Vargas, M. C. (2009). Jurors' perceptions of juvenile defendants: The influence of intellectual disability, abuse history, and confession evidence. Behavioral Sciences and the Law, 27, 401-430. doi: 10.1002/bsl.873

Nunez, N., Dahl, M. J., Tang, C. M., \& Jensen, B. L. (2007). Trial venue decisions in juvenile cases: Mitigating and extralegal factors matter. Legal and Criminological Psychology, 12, 21-39. doi: $10.1348 / 135532505 \times 73768$

Perlin, M. L. (2003). Beyond Atkins: A symposium on the implications of Atkins v. Virginia. New Mexico Law Review, 33, 315-348.

Pittman, T. S., \& Pittman, N. L. (1980). Deprivation of control and the attribution process. Journal of Personality and Social Psychology, 39, 377-389. doi: 10.1037/0022-3514.39.3.377

Redlich, A. D., Ghetti, S., \& Quas, J. A. (2008). Perceptions of children during a police interview: A comparison of alleged victims and suspects. Journal of Applied Social Psychology, 38, 705-735. doi: 10.1111/j.1559-1816.2007.00323.x 
Redlich, A. D., Quas, J. A., \& Ghetti, S. (2008). Perceptions of children during a police interrogation: Guilt, confessions, and interview fairness. Psychology, Crime, and Law, 14, 201-223. doi: $10.1080 / 10683160701652542$

Reppucci, N. D., Michel, J. L., \& Kostelnik, J. O. (2009). Challenging juvenile transfer: Faulty assumptions and misguided policies. In B. L. Bottoms, C. J. Najdowski, \& G. S. Goodman (Eds.), Children as victims, witnesses, and offenders: Psychological science and the law (pp. 295-312). New York: Guilford Press.

Reppucci, N. D., Scott, E., \& Antonishak, J. (2009). Political orientation and perceptions of adolescent autonomy and judicial culpability. Behavioral Sciences and the Law, 27, 29-34. doi: 10.1002/bsl.851

Roper v. Simmons, 543 U.S. 551 (2005).

Salerno, J. M., Najdowski, C. J., Stevenson, M. C., Wiley, T. R. A., Bottoms, B. L., Vaca, Jr., R. A., \& Pimental, P. S. (2010). Psychological mechanisms underlying support for juvenile sex offender registry laws: Prototypes, moral outrage, and perceived threat. Behavioral Sciences and the Law, 28, 58-83. doi: 10.1002/bsl.921

Sandys, M., \& Dillehay, R. C. (1995). First-ballot votes, predeliberation dispositions, and final verdicts in jury trials. Law and Human Behavior, 19, 175-195. doi: 10.1007/BF01499324

Shaver, K. G. (1985). The attribution of blame: Causality, responsibility, and blameworthiness. New York: Springer-Verlag.

Shaw, J. I., \& Skolnick, P. (1995). Effects of prohibitive and informative judicial instructions on jury decision making. Social Behavior and Personality, 23, 319-326. doi: 10.2224/sbp.1995.23.4.319

Shrout, P. E., \& Bolger, N. (2002). Mediation in experimental and nonexperimental studies: New procedures and recommendations. Psychological Methods, 7, 422-445. doi: 10.1037/1082989X.7.4.422

Stalans, L. J., \& Henry, G. T. (1994). Societal views of justice for adolescents accused of murder: Inconsistency between community sentiment and automatic legislative transfers. Law and Human 
Behavior, 18, 675-696. doi: 10.1007/BF01499331

Steinberg, L., \& Scott, E. S. (2003). Less guilty by reason of adolescence: Developmental immaturity, diminished responsibility, and the juvenile death penalty. American Psychologist, 58, 1009-1018. doi: 10.1037/0003-066X.58.12.1009

Taylor, A. B., MacKinnon, D. P., \& Tein, J.-Y. (2008). Tests of the three-path mediated effect. Organizational Research Methods, 11, 241-269. doi: 10.1177/1094428107300344

Tubb, V. A., Wood, J. M., \& Hosch, H. M. (1999). Effects of suggestive interviewing and indirect evidence on child credibility in a sexual abuse case. Journal of Applied Social Psychology, 29, 11111127. doi: 10.1111/j.1559-1816.1999.tb02031.x

Viljoen, J. L., Klaver, J., \& Roesch, R. (2005). Legal decisions of preadolescent and adolescent defendants: Predictors of confessions, pleas, communication with attorneys, and appeals. Law and Human Behavior, 29, 253-277. doi: 10.1007/s10979-005-3613-2

Warden, R., \& Drizin, S. A. (2009). True stories of false confessions. Evanston, IL: Northwestern University Press.

Weiner, B. (1985). An attributional theory of achievement motivation and emotion. Psychological Review, 92, 548-573. doi: 10.1037/0033-295X.92.4.548

Weiner, B. (2006). Social motivation, justice, and the moral emotions. Mahwah, NJ: Lawrence Erlbaum Associates.

Weiner, B., Graham, S., \& Reyna, C. (1997). An attributional examination of retributive versus rehabilitation philosophies of punishment. Social Justice Research, 10, 431-452. doi: 10.1007/BF02683293

Weiten, W., \& Diamond, S. S. (1979). A critical review of the jury simulation paradigm: The case of defendant characteristics. Law and Human Behavior, 3, 71-93.

Wiley, T. R. A., \& Bottoms, B. L. (2009). Effects of defendant sexual orientation on jurors' perceptions of child sexual assault. Law and Human Behavior, 33, 46-60. doi: 10.1007/s10979-008-9131-2 
Woody, W. D., \& Forrest, K. D. (2009). Effects of false-evidence ploys and expert testimony on jurors' verdicts, recommended sentences, and perceptions of confession evidence. Behavioral Sciences and the Law, 27, 333-360. doi: 10.1002/bsl.865 


\section{Footnote}

${ }^{1}$ Perceived confession truthfulness was not examined as a potential mediator of the effect of confession voluntariness on juvenile court sentence recommendations because only 8 jurors who recommended that the juvenile be tried in juvenile court thought the confession was not true, and none of those 8 jurors recommended sentencing the juvenile to prison.

${ }^{2}$ Jurors' retributive sentencing goals were not explored as a potential mediator of the effect of disability status on verdicts because only jurors who actually voted guilty rendered that judgment. 
Table 1. Main Effects of Confession Evidence and Disability Status on Jurors' Judgments

\begin{tabular}{|c|c|c|c|c|c|c|c|c|c|c|}
\hline \multirow[b]{3}{*}{ Dichotomous measures } & \multirow[b]{3}{*}{ Marginal } & \multicolumn{5}{|c|}{ Confession Evidence } & \multicolumn{4}{|c|}{ Disability Status } \\
\hline & & & Manip & pulated & Perc & ceived & Mani & ipulated & Per & rceived \\
\hline & & $\begin{array}{l}\text { None } \\
(n=86)\end{array}$ & $\begin{array}{l}\text { Coerced } \\
(n=87)\end{array}$ & $\begin{array}{c}\text { Voluntary } \\
(n=97)\end{array}$ & $\begin{array}{l}\text { Coerced } \\
(n=66)\end{array}$ & $\begin{array}{l}\text { Voluntary } \\
(n=118)\end{array}$ & $\begin{array}{l}\text { Disabled } \\
(n=142)\end{array}$ & $\begin{array}{c}\text { Nondisabled } \\
(n=128)\end{array}$ & $\begin{array}{l}\text { Disabled } \\
(n=129)\end{array}$ & $\begin{array}{c}\text { Nondisabled } \\
(n=141)\end{array}$ \\
\hline $\begin{array}{l}\text { Suspicions of guilt } \\
\text { (\% guilty) }\end{array}$ & $79 \%$ & $76 \%$ & $72 \%$ & $87 \%$ & $61 \%$ & $91 \%$ & $82 \%$ & $74 \%$ & $81 \%$ & $76 \%$ \\
\hline $\begin{array}{l}\text { Trial venue recommendation } \\
\text { (\% adult court) }\end{array}$ & $40 \%$ & $39 \%$ & $39 \%$ & $41 \%$ & $27 \%$ & $48 \%$ & $22 \%$ & $60 \%$ & $19 \%$ & $59 \%$ \\
\hline $\begin{array}{l}\text { Juvenile court sentence } \\
\text { (\% prison) }\end{array}$ & $45 \%$ & $47 \%$ & $53 \%$ & $39 \%$ & $24 \%$ & $50 \%$ & $27 \%$ & $65 \%$ & $24 \%$ & $62 \%$ \\
\hline $\begin{array}{l}\text { Adult court sentence } \\
\text { (\% prison) }\end{array}$ & $78 \%$ & $87 \%$ & $77 \%$ & $73 \%$ & $48 \%$ & $82 \%$ & $73 \%$ & $82 \%$ & $73 \%$ & $82 \%$ \\
\hline $\begin{array}{l}\text { Continuous measures: } \\
1=\text { not at all, } 6=\text { completely }\end{array}$ & $\begin{array}{c}M \\
(S D)\end{array}$ & $\begin{array}{c}M \\
(S D)\end{array}$ & $\begin{array}{c}M \\
(S D)\end{array}$ & $\begin{array}{c}M \\
(S D) \\
\end{array}$ & $\begin{array}{c}M \\
(S D)\end{array}$ & $\begin{array}{c}M \\
(S D)\end{array}$ & $\begin{array}{c}M \\
(S D)\end{array}$ & $\begin{array}{c}M \\
(S D)\end{array}$ & $\begin{array}{c}M \\
(S D) \\
\end{array}$ & $\begin{array}{c}M \\
(S D) \\
\end{array}$ \\
\hline Perceived suggestibility & $\begin{array}{l}3.15 \\
(.91)\end{array}$ & $\begin{array}{l}2.90 \\
(.66)\end{array}$ & $\begin{array}{c}3.43 \\
(1.00)\end{array}$ & $\begin{array}{l}3.12 \\
(.94)\end{array}$ & $\begin{array}{l}3.83 \\
(.87)\end{array}$ & $\begin{array}{l}2.95 \\
(.90)\end{array}$ & $\begin{array}{l}3.28 \\
(.93)\end{array}$ & $\begin{array}{l}3.00 \\
(.85)\end{array}$ & $\begin{array}{l}3.34 \\
(.96)\end{array}$ & $\begin{array}{l}2.98 \\
(.82)\end{array}$ \\
\hline Sympathy & $\begin{array}{l}2.96 \\
(1.18)\end{array}$ & $\begin{array}{c}3.11 \\
(1.12)\end{array}$ & $\begin{array}{c}3.02 \\
(1.20)\end{array}$ & $\begin{array}{c}2.76 \\
(1.18)\end{array}$ & $\begin{array}{l}3.30 \\
(1.09)\end{array}$ & $\begin{array}{c}2.66 \\
(1.20)\end{array}$ & $\begin{array}{l}3.16 \\
(1.22)\end{array}$ & $\begin{array}{c}2.73 \\
(1.08)\end{array}$ & $\begin{array}{l}3.25 \\
(1.18)\end{array}$ & $\begin{array}{c}2.69 \\
(1.11)\end{array}$ \\
\hline Anger & $\begin{array}{c}2.69 \\
(1.23)\end{array}$ & $\begin{array}{c}2.38 \\
(1.20)\end{array}$ & $\begin{array}{c}2.75 \\
(1.21)\end{array}$ & $\begin{array}{c}2.91 \\
(1.23)\end{array}$ & $\begin{array}{c}2.52 \\
(1.13)\end{array}$ & $\begin{array}{c}3.01 \\
(1.24)\end{array}$ & $\begin{array}{c}2.51 \\
(1.16)\end{array}$ & $\begin{array}{c}2.89 \\
(1.28)\end{array}$ & $\begin{array}{c}2.54 \\
(1.17)\end{array}$ & $\begin{array}{c}2.82 \\
(1.28)\end{array}$ \\
\hline Internal attributions & $\begin{array}{l}2.45 \\
(.81)\end{array}$ & $\begin{array}{l}2.33 \\
(.85)\end{array}$ & $\begin{array}{l}2.51 \\
(.74)\end{array}$ & $\begin{array}{l}2.51 \\
(.82)\end{array}$ & $\begin{array}{l}2.36 \\
(.75)\end{array}$ & $\begin{array}{l}2.56 \\
(.79)\end{array}$ & $\begin{array}{l}2.27 \\
(.71)\end{array}$ & $\begin{array}{l}2.67 \\
(.71)\end{array}$ & $\begin{array}{l}2.33 \\
(.74)\end{array}$ & $\begin{array}{l}2.57 \\
(.86)\end{array}$ \\
\hline External attributions & $\begin{array}{c}4.22 \\
(1.03)\end{array}$ & $\begin{array}{l}4.32 \\
(.91)\end{array}$ & $\begin{array}{l}4.24 \\
(.96)\end{array}$ & $\begin{array}{c}4.14 \\
(1.15)\end{array}$ & $\begin{array}{c}4.33 \\
(1.02)\end{array}$ & $\begin{array}{c}4.13 \\
(1.09)\end{array}$ & $\begin{array}{c}4.27 \\
(1.07)\end{array}$ & $\begin{array}{l}4.17 \\
(.98)\end{array}$ & $\begin{array}{c}4.24 \\
(1.08)\end{array}$ & $\begin{array}{l}4.21 \\
(.98)\end{array}$ \\
\hline Attributions of causal control & $\begin{array}{l}4.64 \\
(.97)\end{array}$ & $\begin{array}{l}4.65 \\
(.99)\end{array}$ & $\begin{array}{l}4.64 \\
(.99)\end{array}$ & $\begin{array}{l}4.63 \\
(.94)\end{array}$ & $\begin{array}{l}4.25 \\
(.98)\end{array}$ & $\begin{array}{l}4.78 \\
(.91)\end{array}$ & $\begin{array}{c}4.34 \\
(.98)\end{array}$ & $\begin{array}{l}4.99 \\
(.83)\end{array}$ & $\begin{array}{l}4.23 \\
(.97)\end{array}$ & $\begin{array}{l}5.03 \\
(.79)\end{array}$ \\
\hline Attributions of causal stability & $\begin{array}{c}4.38 \\
(1.03)\end{array}$ & $\begin{array}{c}4.21 \\
(1.07)\end{array}$ & $\begin{array}{l}4.44 \\
(.98)\end{array}$ & $\begin{array}{l}4.44 \\
(.98)\end{array}$ & $\begin{array}{c}4.23 \\
(1.00)\end{array}$ & $\begin{array}{l}4.54 \\
(.99)\end{array}$ & $\begin{array}{c}4.30 \\
(1.08)\end{array}$ & $\begin{array}{l}4.48 \\
(.96)\end{array}$ & $\begin{array}{c}4.28 \\
(1.05)\end{array}$ & $\begin{array}{l}4.48 \\
(.99)\end{array}$ \\
\hline Perceived responsibility & $\begin{array}{c}4.39 \\
(1.18)\end{array}$ & $\begin{array}{c}4.18 \\
(1.28)\end{array}$ & $\begin{array}{c}4.49 \\
(1.11)\end{array}$ & $\begin{array}{c}4.47 \\
(1.14)\end{array}$ & $\begin{array}{c}3.93 \\
(1.12)\end{array}$ & $\begin{array}{c}4.69 \\
(1.05)\end{array}$ & $\begin{array}{c}4.28 \\
(1.18)\end{array}$ & $\begin{array}{c}4.52 \\
(1.17)\end{array}$ & $\begin{array}{c}4.25 \\
(1.16)\end{array}$ & $\begin{array}{c}4.52 \\
(1.18)\end{array}$ \\
\hline Rehabilitative sentencing goal & $\begin{array}{c}4.48 \\
(1.09)\end{array}$ & $\begin{array}{l}4.54 \\
(.96)\end{array}$ & $\begin{array}{c}4.55 \\
(1.11)\end{array}$ & $\begin{array}{c}4.39 \\
(1.16)\end{array}$ & $\begin{array}{c}4.71 \\
(1.04)\end{array}$ & $\begin{array}{c}4.38 \\
(1.16)\end{array}$ & $\begin{array}{c}4.42 \\
(1.14)\end{array}$ & $\begin{array}{c}3.93 \\
(1.41)\end{array}$ & $\begin{array}{c}4.42 \\
(1.18)\end{array}$ & $\begin{array}{c}4.53 \\
(1.02)\end{array}$ \\
\hline Retributive sentencing goal & $\begin{array}{c}3.77 \\
(1.31)\end{array}$ & $\begin{array}{c}3.54 \\
(1.48)\end{array}$ & $\begin{array}{c}4.07 \\
(1.17)\end{array}$ & $\begin{array}{c}3.69 \\
(1.28)\end{array}$ & $\begin{array}{c}3.50 \\
(1.41)\end{array}$ & $\begin{array}{c}3.96 \\
(1.17)\end{array}$ & $\begin{array}{c}3.62 \\
(1.20)\end{array}$ & $\begin{array}{c}4.54 \\
(1.04)\end{array}$ & $\begin{array}{c}3.52 \\
(1.21)\end{array}$ & $\begin{array}{c}3.97 \\
(1.36)\end{array}$ \\
\hline
\end{tabular}


Table 2. Test Statistics and Effect Sizes as a Function of Manipulated Variables Analyses and Perceived Variables Analyses

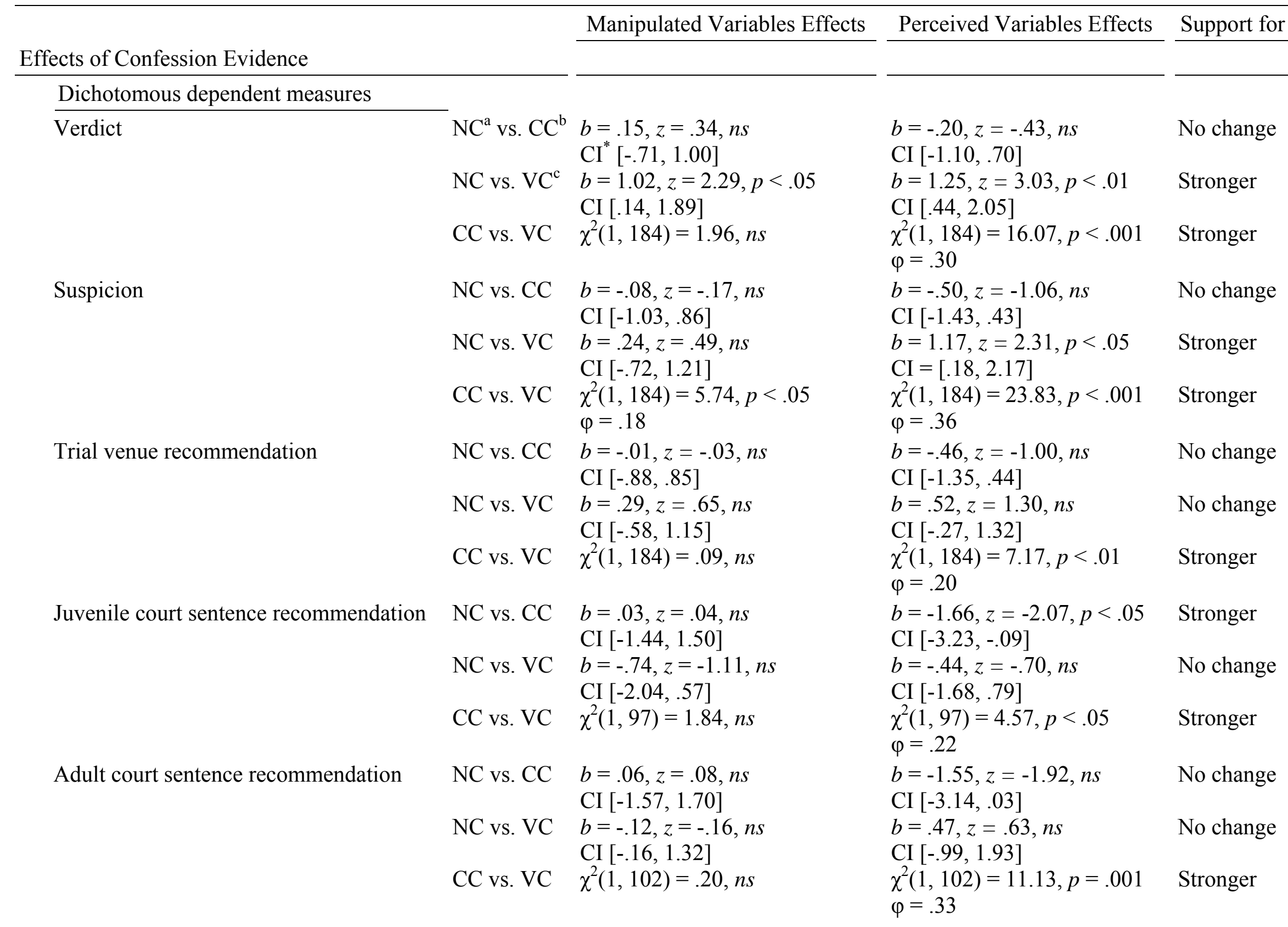


Table 2. (continued)

\begin{tabular}{|c|c|c|c|c|}
\hline \multirow{2}{*}{\multicolumn{2}{|c|}{ Effects of Confession Evidence }} & \multirow[t]{2}{*}{ Manipulated Variables Effects } & \multirow[t]{2}{*}{ Perceived Variables Effects } & \multirow[t]{2}{*}{ Support for Hypotheses } \\
\hline & & & & \\
\hline Perceived confession truthfulness & CC vs. VC & $\begin{array}{l}b=-.63, z=-1.35, n s \\
\text { CI }[-1.53, .28]\end{array}$ & $\begin{array}{l}b=1.98, z=4.04, p<.001 \\
\text { CI }[1.02,2.94]\end{array}$ & Stronger \\
\hline \multicolumn{5}{|l|}{ Continuous dependent measures } \\
\hline \multirow[t]{4}{*}{ Perceived suggestibility } & Omnibus & $\begin{array}{l}F(2,264)=8.24, p<.001 \\
\text { partial } \eta^{2}=.05\end{array}$ & $\begin{array}{l}F(2,264)=30.67, p<.001 \\
\text { partial } \eta^{2}=.19\end{array}$ & Stronger \\
\hline & $\mathrm{NC}$ vs. CC & $\begin{array}{l}F(1,264)=16.08, p<.001 \\
\text { Cohen's } d=.63\end{array}$ & $\begin{array}{l}F(1,264)=49.77, p<.001 \\
d=1.20\end{array}$ & Stronger \\
\hline & NC vs. VC & $F(1,264)=2.56, n s$ & $F(1,264)=.34, n s$ & No change \\
\hline & CC vs. VC & $\begin{array}{l}F(1,264)=6.37, p=.01 \\
d=.32\end{array}$ & $\begin{array}{l}F(1,264)=48.49, p<.001 \\
d=.99\end{array}$ & Stronger \\
\hline \multirow[t]{4}{*}{ Sympathy } & Omnibus & $F(2,264)=2.22, n s$ & $\begin{array}{l}F(2,264)=7.95, p<.001 \\
\text { partial } \eta^{2}=.06\end{array}$ & Stronger \\
\hline & NC vs. CC & -- & $F(1,264)=1.03, n s$ & No change \\
\hline & $\mathrm{NC}$ vs. VC & -- & $\begin{array}{l}F(1,264)=8.02, p<.01 \\
d=.39\end{array}$ & Stronger \\
\hline & CC vs. VC & -- & $\begin{array}{l}F(1,264)=13.65, p<.001 \\
d=.56\end{array}$ & Stronger \\
\hline \multirow[t]{4}{*}{ Anger } & Omnibus & $\begin{array}{l}F(2,264)=4.51, p=.01 \\
\text { partial } \eta^{2}=.02\end{array}$ & $\begin{array}{l}F(2,264)=7.69, p=.001 \\
\text { partial } \eta^{2}=.06\end{array}$ & Stronger \\
\hline & $\mathrm{NC}$ vs. $\mathrm{CC}$ & $F(1,264)=3.63, n s$ & $F(1,264)=.47, n s$ & No change \\
\hline & NC vs. VC & $\begin{array}{l}F(1,264)=9.06, p<.01 \\
d=.44\end{array}$ & $\begin{array}{l}F(1,264)=13.54, p<.001 \\
d=.52\end{array}$ & Stronger \\
\hline & CC vs. VC & $F(1,264)=1.05, n s$ & $\begin{array}{l}F(1,264)=7.11, p<.01 \\
d=.41\end{array}$ & Stronger \\
\hline Internal attributions & Omnibus & $F(2,204)=1.50, n s$ & $F(2,204)=1.94, n s$ & No change \\
\hline External attributions & Omnibus & $F(2,204)=.56, n s$ & $F(2,204)=.88, n s$ & No change \\
\hline
\end{tabular}


Table 2. (continued)

\begin{tabular}{|c|c|c|c|c|}
\hline & & Manipulated Variables Effects & Perceived Variables Effects & Support for Hypotheses \\
\hline \multicolumn{5}{|l|}{ Effects of Confession Evidence } \\
\hline \multirow[t]{4}{*}{ Attributions of causal control } & Omnibus & $F(2,204)=.01, n s$ & $\begin{array}{l}F(2,204)=4.99, p<.01 \\
\text { partial } \eta^{2}=.05\end{array}$ & Stronger \\
\hline & $\mathrm{NC}$ vs. $\mathrm{CC}$ & -- & $\begin{array}{l}F(1,204)=5.36, p<.05 \\
d=.41\end{array}$ & Stronger \\
\hline & $\mathrm{NC}$ vs. VC & -- & $F(1,204)=.53, n s$ & No change \\
\hline & CC vs. VC & -- & $\begin{array}{l}F(1,204)=9.95, p<.01 \\
d=.56\end{array}$ & Stronger \\
\hline Attributions of causal stability & Omnibus & $F(2,204)=1.57, n s$ & $F(2,204)=2.61, n s$ & No change \\
\hline \multirow[t]{4}{*}{ Perceived responsibility } & Omnibus & $F(2,206)=1.69, n s$ & $\begin{array}{l}F(2,206)=7.78, p=.001 \\
\text { partial } \eta^{2}=.07\end{array}$ & Stronger \\
\hline & $\mathrm{NC}$ vs. $\mathrm{CC}$ & -- & $F(1,206)=1.27, n s$ & No change \\
\hline & NC vs. VC & -- & $\begin{array}{l}F(1,206)=7.56, p<.01 \\
d=.44\end{array}$ & Stronger \\
\hline & CC vs. VC & -- & $\begin{array}{l}F(1,206)=12.65, p<.001 \\
d=.70\end{array}$ & Stronger \\
\hline Rehabilitative sentencing goal & Omnibus & $F(2,134)=.40, n s$ & $F(2,134)=1.35, n s$ & No change \\
\hline Retributive sentencing goal & Omnibus & $F(2,134)=1.90, n s$ & $F(2,134)=2.19, n s$ & No change \\
\hline \multicolumn{5}{|l|}{ Effects of Disability Status } \\
\hline \multicolumn{5}{|l|}{ Dichotomous dependent measures } \\
\hline Verdict & & $\begin{array}{l}b=-.07, z=-.16, n s \\
\mathrm{CI}^{*}[-.91, .78]\end{array}$ & $\begin{array}{l}\mathrm{b}=-.01, \mathrm{z}=-.03, n s \\
\mathrm{CI}[-.86, .83]\end{array}$ & No change \\
\hline Suspicion & & $\begin{array}{l}b=.24, z=.49, n s \\
\mathrm{CI}[-.72,1.21]\end{array}$ & $\begin{array}{l}b=.55, z=1.10, n s \\
\text { CI }[-.43,1.54]\end{array}$ & No change \\
\hline Trial venue recommendation & & $\begin{array}{l}b=-1.51, z=-3.20, p=.001 \\
\text { CI }[-2.44,-.59]\end{array}$ & $\begin{array}{l}b=-1.49, z=-3.12, p<.01 \\
\text { CI }[-2.42,-.55]\end{array}$ & Weaker \\
\hline Juvenile court sentence recommendation & & $\begin{array}{l}b=-1.91, z=-2.55, p=.01 \\
\text { CI }[-3.37,-.44]\end{array}$ & $\begin{array}{l}b=-2.19, z=-2.85, p<.01 \\
\text { CI }[-3.70,-.68]\end{array}$ & Stronger \\
\hline Adult court sentence recommendation & & $\begin{array}{l}b=.46, z=.51, n s \\
\text { CI }[-1.30,2.22]\end{array}$ & $\begin{array}{l}b=.34, z=.38, n s \\
\text { CI }[-1.42,2.10]\end{array}$ & No change \\
\hline
\end{tabular}


Table 2. (continued)

\begin{tabular}{|c|c|c|c|}
\hline \multirow[b]{2}{*}{ Effects of Disability Status } & \multirow[t]{2}{*}{ Manipulated Variables Effects } & \multirow[t]{2}{*}{ Perceived Variables Effects } & \multirow[t]{2}{*}{ Support for Hypotheses } \\
\hline & & & \\
\hline Perceived confession truthfulness & $\begin{array}{l}b=.08, z=.16, n s \\
\text { CI }[-.84,1.00]\end{array}$ & $\begin{array}{l}b=-.27, z=-.54, n s \\
\text { CI }[-1.23, .70]\end{array}$ & No change \\
\hline \multicolumn{4}{|l|}{ Continuous dependent measures } \\
\hline Perceived suggestibility & $\begin{array}{l}F(1,264)=6.97, p<.01 \\
\text { Cohen's } d=.31\end{array}$ & $\begin{array}{l}F(1,264)=11.72, p=.001 \\
d=.40\end{array}$ & Stronger \\
\hline Sympathy & $\begin{array}{l}F(1,264)=10.15, p<.01 \\
d=.37\end{array}$ & $\begin{array}{l}F(1,264)=15.77, p<.01 \\
d=.49\end{array}$ & Stronger \\
\hline Anger & $\begin{array}{l}F(1,264)=6.86, p<.01 \\
d=.31\end{array}$ & $F(1,264)=3.54, n s$ & Weaker \\
\hline Internal attributions & $\begin{array}{l}F(1,204)=12.20, p=.001 \\
d=.56\end{array}$ & $\begin{array}{l}F(1,204)=5.20, p<.05 \\
d=.30\end{array}$ & Weaker \\
\hline External attributions & $F(1,204)=.54, n s$ & $F(1,204)=.02, n s$ & No change \\
\hline Attributions of causal control & $\begin{array}{l}F(1,204)=25.64, p<.001 \\
d=.72\end{array}$ & $\begin{array}{l}F(1,204)=38.64, p<.001 \\
d=.90\end{array}$ & Stronger \\
\hline Attributions of causal stability & $F(1,204)=1.48, n s$ & $F(1,204)=.63, n s$ & No change \\
\hline Perceived responsibility & $F(1,206)=1.53, n s$ & $F(1,206)=1.59, n s$ & No change \\
\hline Rehabilitative sentencing goal & $F(1,134)=.42, n s$ & $F(1,134)=.22, n s$ & No change \\
\hline Retributive sentencing goal & $F(1,134)=2.94, n s$ & $\begin{array}{l}F(1,134)=6.79, p=.01 \\
d=.35\end{array}$ & Stronger \\
\hline
\end{tabular}

Notes. ${ }^{\mathrm{a}} \mathrm{NC}=$ No confession. ${ }^{\mathrm{b}} \mathrm{CC}=$ Coerced confession. ${ }^{\mathrm{c}} \mathrm{VC}=$ Voluntary confession. ${ }^{*}$ All confidence intervals are stated at the $95 \%$ confidence level. 
Table 3. Logistic Regression Analysis Testing for Potential Mediators of Manipulated Confession Evidence Effect

\begin{tabular}{llrrrrr}
\hline Dependent measure & Predictors & $B$ & $S E$ & Wald & $p$ & OR \\
\hline Suspicion of guilt & & & & & & \\
& Confession voluntariness & -.57 & .48 & 1.40 & .24 & .56 \\
& Perceived suggestibility scale & -1.94 & .35 & 31.40 & $<.001$ & .14 \\
& Sympathy scale & -.36 & .22 & 2.79 & .10 & .70 \\
& $\chi^{2}(3,184)=71.02, p<.001$ & & & & & \\
\hline
\end{tabular}


Table 4. Logistic Regression Analyses Testing for Potential Mediators of Manipulated Intellectual Disability

Effects

\begin{tabular}{|c|c|c|c|c|c|c|}
\hline Dependent measure & Predictors & $B$ & $S E$ & Wald & $p$ & OR \\
\hline \multicolumn{7}{|c|}{ Trial venue recommendations } \\
\hline & Disability status & -1.40 & .34 & 16.84 & $<.001$ & .25 \\
\hline & Internal attributions scale & .44 & .23 & 5.75 & .02 & 1.73 \\
\hline & Attributions of causal control scale & .48 & .21 & 5.41 & .02 & 1.62 \\
\hline & Sympathy scale & -.47 & .16 & 9.14 & .003 & .62 \\
\hline & Anger & .06 & .14 & .20 & .66 & 1.07 \\
\hline \multicolumn{7}{|c|}{$\chi^{2}(5,209)=70.25, p<.001$} \\
\hline \multicolumn{7}{|c|}{ Juvenile court sentence recommendations } \\
\hline & Disability status & -1.59 & .43 & 13.73 & $<.001$ & .21 \\
\hline & Internal attributions scale & .22 & .27 & 67 & .41 & 1.25 \\
\hline & Attributions of causal control scale & .11 & .26 & .18 & .67 & 1.11 \\
\hline & Sympathy scale & -.41 & .19 & 4.44 & .04 & .67 \\
\hline & $\begin{array}{l}\text { Retributive sentencing goal } \\
\qquad \chi^{2}(5,128)=29.12, p<.001\end{array}$ & -.10 & .17 & .33 & .57 & .91 \\
\hline
\end{tabular}


Table 5. Logistic Regression Analyses Testing for Potential Mediators of Perceived Confession Voluntariness Effects

\begin{tabular}{|c|c|c|c|c|c|c|}
\hline Dependent measure & Predictors & $B$ & $S E$ & Wald & $p$ & $O R$ \\
\hline \multicolumn{7}{|l|}{ Verdict } \\
\hline & Confession voluntariness & .14 & .47 & .09 & .76 & 1.15 \\
\hline & Perceived suggestibility scale & -.76 & .30 & 6.30 & .01 & .47 \\
\hline & Perceived confession truthfulness & 1.77 & .54 & 10.64 & .001 & 5.86 \\
\hline & Sympathy scale & -.15 & .18 & .69 & .41 & .87 \\
\hline & Anger & .57 & .19 & 9.34 & .002 & 1.76 \\
\hline \multicolumn{7}{|c|}{$\chi^{2}(5,184)=87.75, p<.001$} \\
\hline \multicolumn{7}{|l|}{ Suspicion of guilt } \\
\hline & Confession voluntariness & -.17 & .65 & .07 & .79 & .84 \\
\hline & Perceived suggestibility scale & -.78 & .47 & 2.71 & .10 & .46 \\
\hline & Perceived confession truthfulness & 4.64 & 1.18 & 15.37 & $<.001$ & 103.58 \\
\hline & Sympathy scale & -.80 & .32 & 6.39 & .01 & .45 \\
\hline & Anger & 1.14 & .42 & 7.30 & .007 & 3.14 \\
\hline \multicolumn{7}{|c|}{$\chi^{2}(5,184)=115.24, p<.001$} \\
\hline \multicolumn{7}{|c|}{ Trial venue recommendations } \\
\hline & Confession voluntariness & -.21 & .39 & .28 & .60 & .81 \\
\hline & Perceived suggestibility scale & -.41 & .25 & 2.69 & .10 & .67 \\
\hline & Perceived confession truthfulness & .18 & .51 & .13 & .72 & 1.20 \\
\hline & Sympathy scale & -.41 & .15 & 7.62 & .006 & .66 \\
\hline & Anger & .11 & .14 & .56 & .46 & 1.11 \\
\hline \multicolumn{7}{|c|}{$\chi^{2}(5,184)=28.58, p<.001$} \\
\hline \multicolumn{7}{|c|}{ Juvenile court sentence recommendations $^{1}$} \\
\hline & Confession voluntariness & -.68 & .63 & 1.18 & .28 & .51 \\
\hline & Perceived suggestibility scale & -.65 & .36 & 3.32 & .07 & .52 \\
\hline & Sympathy scale & -.26 & .20 & 1.65 & .20 & .77 \\
\hline & Anger & .21 & .18 & 1.35 & .25 & 1.24 \\
\hline \multicolumn{7}{|c|}{$\chi^{2}(4,97)=15.12, p<.01$} \\
\hline \multicolumn{7}{|c|}{ Adult court sentence recommendations } \\
\hline & Confession voluntariness & -1.13 & .63 & 3.27 & .07 & .32 \\
\hline & Perceived suggestibility scale & -.03 & .41 & .01 & .95 & .97 \\
\hline & Perceived confession truthfulness & 1.33 & 1.00 & 1.78 & .18 & 3.79 \\
\hline & Sympathy scale & -.24 & .23 & 1.13 & .29 & .79 \\
\hline & Anger & .26 & .22 & 1.41 & .24 & 1.30 \\
\hline \multicolumn{7}{|c|}{$\chi^{2}(5,102)=16.86, p<.01$} \\
\hline
\end{tabular}


Table 6. Logistic Regression Analyses Testing for Potential Mediators of Perceived Intellectual Disability Effects

\begin{tabular}{|c|c|c|c|c|c|c|}
\hline Dependent measure & Predictors & $B$ & $S E$ & Wald & $p$ & $O R$ \\
\hline \multicolumn{7}{|c|}{ Verdicts $^{2}$} \\
\hline & Disability status & -.23 & .33 & .47 & .49 & .80 \\
\hline & Internal attributions scale & .66 & .21 & 9.37 & .002 & 1.93 \\
\hline & Attributions of causal control scale & .10 & .18 & .33 & .57 & 1.11 \\
\hline & Sympathy scale & -.17 & .14 & 1.57 & .21 & .84 \\
\hline \multicolumn{7}{|c|}{$\chi^{2}(4,210)=18.06, p=.001$} \\
\hline \multicolumn{7}{|c|}{ Trial venue recommendations } \\
\hline & Disability status & -1.25 & .43 & 8.61 & .003 & .29 \\
\hline & Internal attributions scale & .53 & .28 & 3.61 & .06 & 1.70 \\
\hline & Attributions of causal control scale & .52 & .27 & 3.82 & .05 & 1.69 \\
\hline & Sympathy scale & -.42 & .20 & 4.46 & .04 & .66 \\
\hline & $\begin{array}{l}\text { Retributive sentencing goal } \\
\qquad \chi^{2}(5,136)=43.38, p<.001\end{array}$ & .05 & .18 & .08 & .78 & 1.05 \\
\hline \multicolumn{7}{|c|}{ ce recommendation } \\
\hline & Disability status & -1.48 & .43 & 11.59 & .001 & .23 \\
\hline & Internal attributions scale & .34 & .28 & 1.46 & .23 & 1.40 \\
\hline & Attributions of causal control scale & .06 & .26 & .05 & .82 & 1.06 \\
\hline & Sympathy scale & -.37 & .20 & 3.45 & .06 & .69 \\
\hline & $\begin{array}{l}\text { Retributive sentencing goal } \\
\qquad \chi^{2}(5,128)=26.65, p<.001\end{array}$ & -.05 & .18 & .08 & .77 & .95 \\
\hline
\end{tabular}


Figure 1

Jurors' Verdicts as a Function of Manipulated Confession Evidence and Perceived Confession

Voluntariness

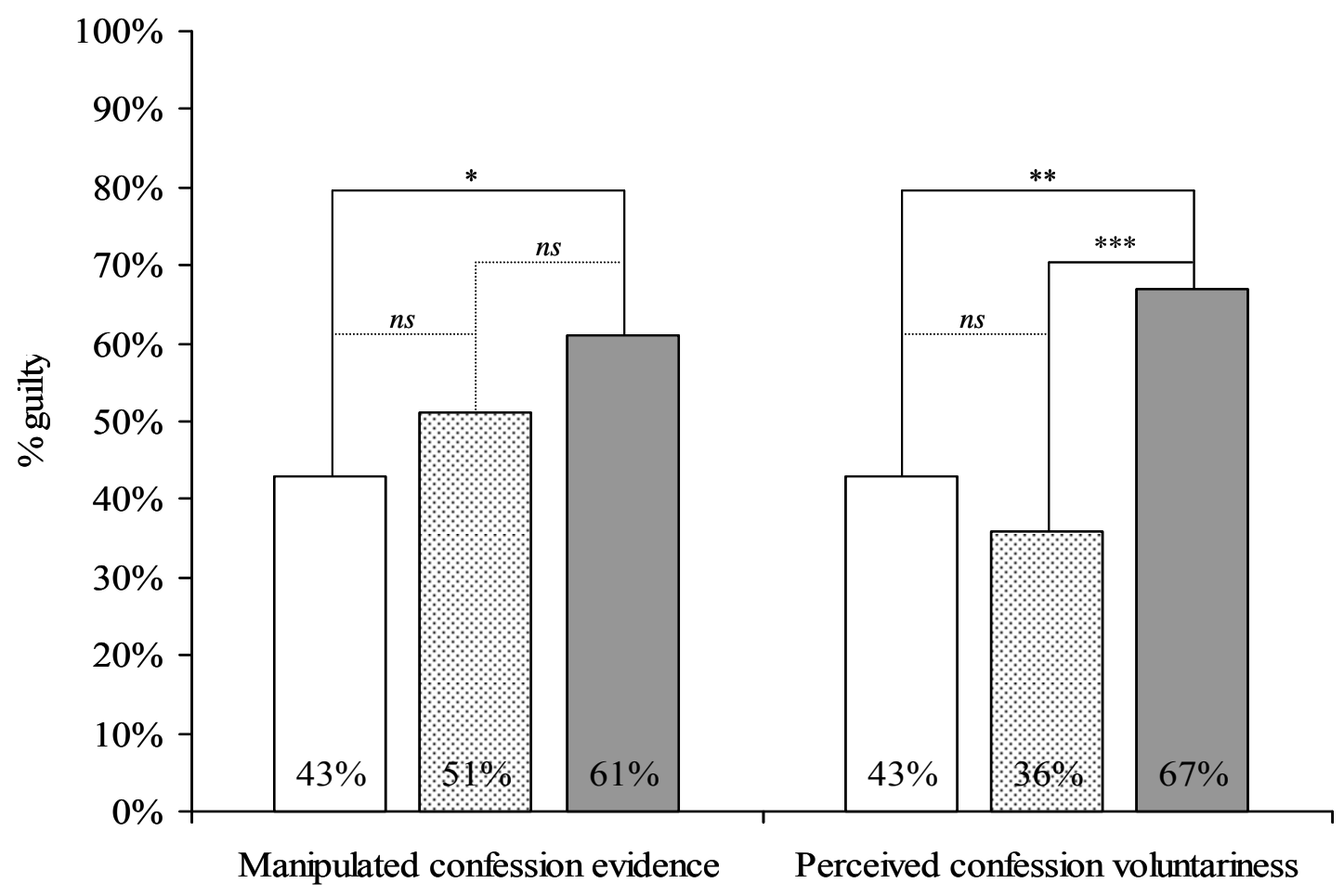

$\square$ No confession

웅 Coerced confession

$\square$ Voluntary confession

Note. Significant differences denoted as $* p<.05, * * p<.01$, and $* * * p<.001$. Nonsignificant differences are denoted as $n s$. 
Figure 2

Trimmed Model of the Effect of Manipulated Confession Voluntariness on Suspicions of Guilt

$$
B=.32, p<.05 \quad B=-.23, p<.001
$$

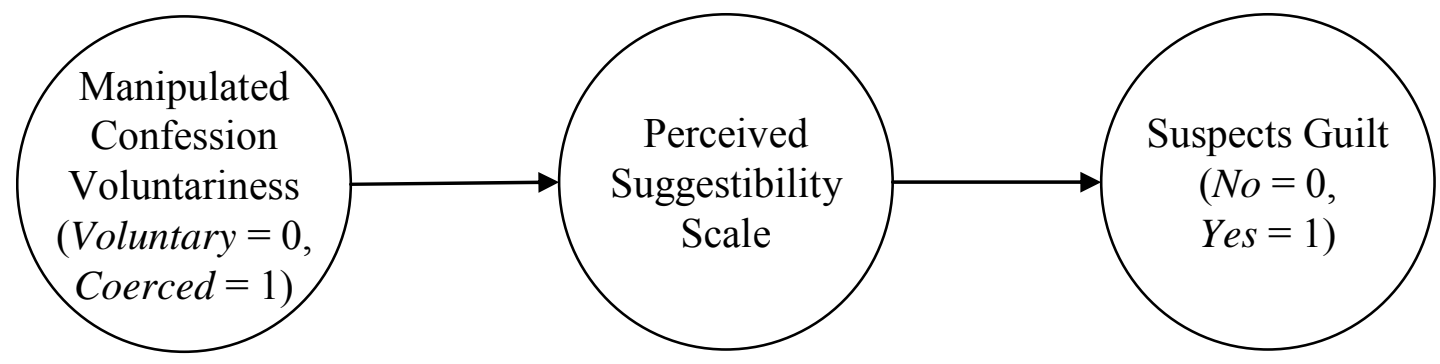

$\chi^{2}(1,184)=2.00, n s ; \mathrm{CFI}=.99 ; \mathrm{RMSEA}=.07$ 
Figure 3

Trimmed Models of the Effect of Manipulated Disability Status on (a) Trial Venue Recommendations among Jurors with Suspicions of Guilt and (b) Juvenile Court Sentence Recommendations among Jurors who Voted Guilty

a.

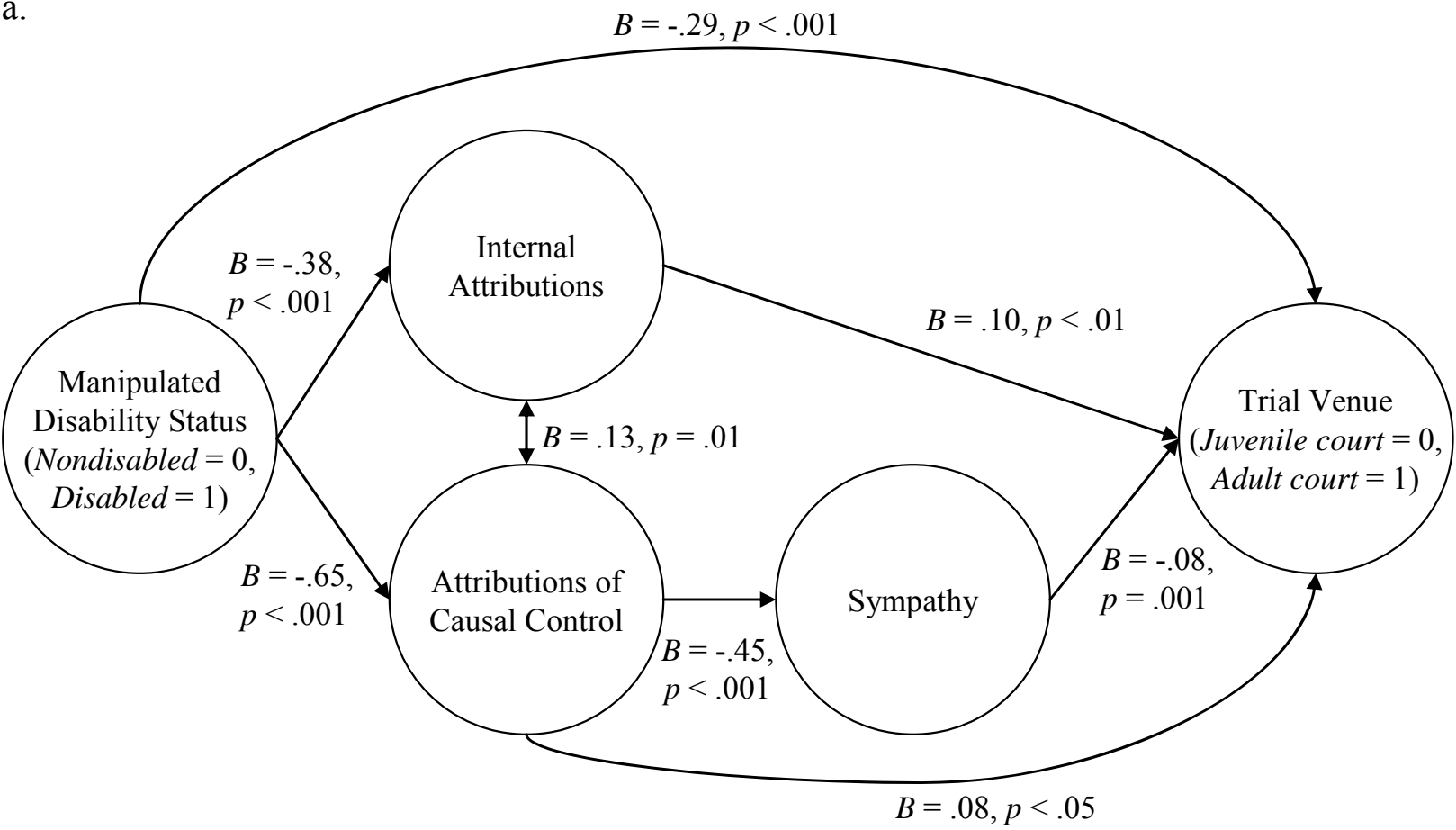

$\chi^{2}(2,209)=1.55, n s, \mathrm{CFI}=1.00, \mathrm{RMSEA}=.00$

b.

$$
B=-.34, p<.001
$$

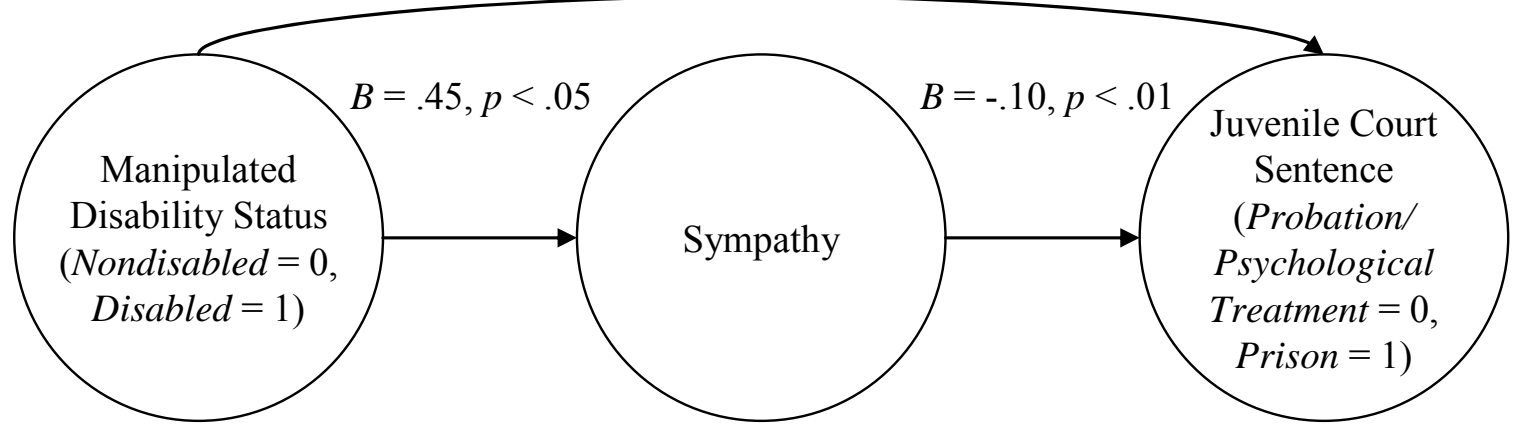


Figure 4

Trimmed Models of the Effect of Perceived Confession Voluntariness on (a) Suspicions of Guilt, (b)

Verdicts, and (c) Trial Venue Recommendations

a.

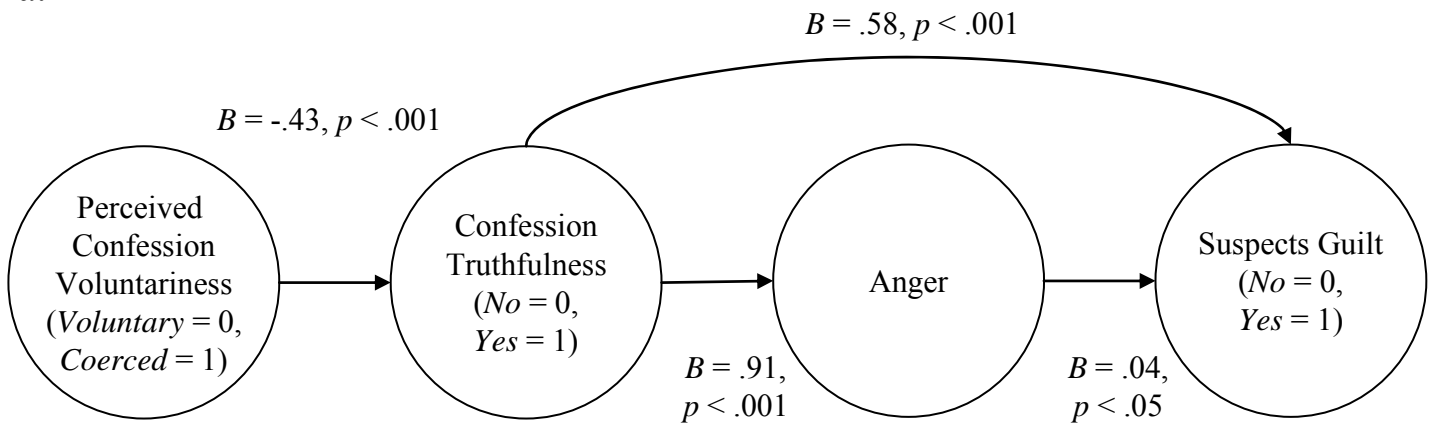

$\chi^{2}(2,184)=1.16, n s, \mathrm{CFI}=1.00, \mathrm{RMSEA}=.00$

b.

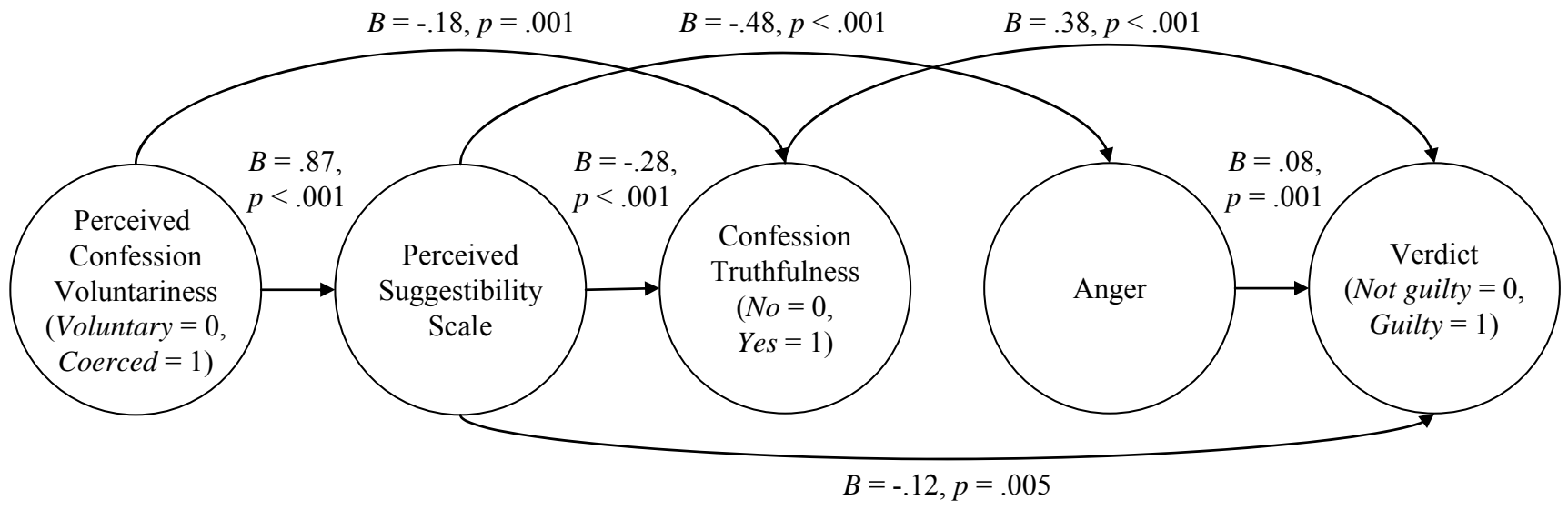

$\chi^{2}(3,184)=2.98, n s, \mathrm{CFI}=1.00, \mathrm{RMSEA}=.00$

c.

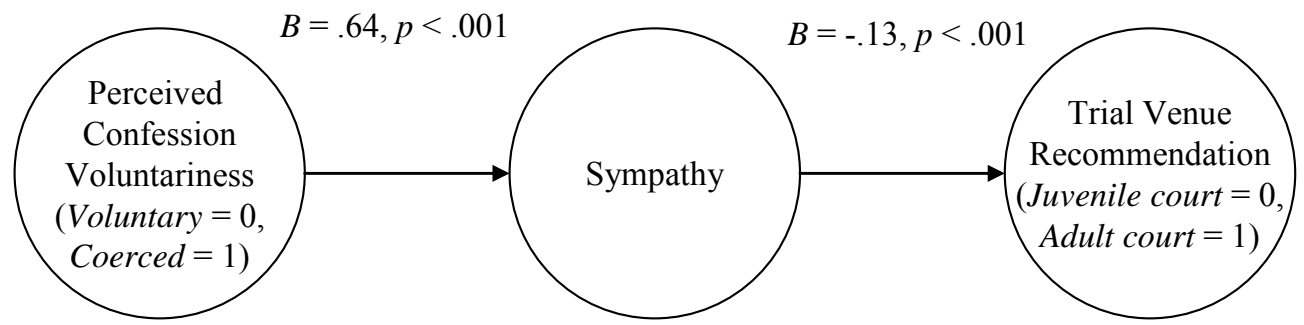

$\chi^{2}(1,184)=3.07, n s, \mathrm{CFI}=.93, \mathrm{RMSEA}=.11$ 
Figure 5

Trimmed Models of the Effect of Perceived Disability Status on (a) Verdicts and (b) Trial Venue

Recommendations among Jurors with Suspicions of Guilt

a.

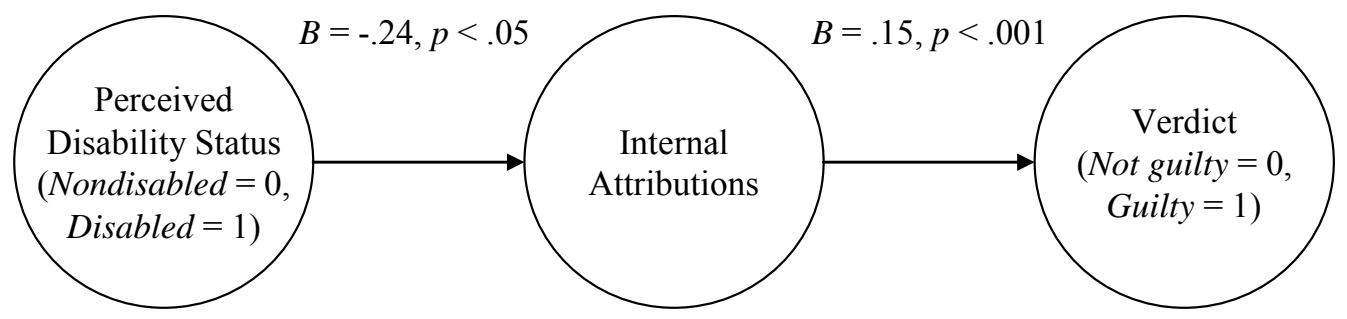

$\chi^{2}(1,210)=1.73, n s, \mathrm{CFI}=.96, \mathrm{RMSEA}=.06$

b.

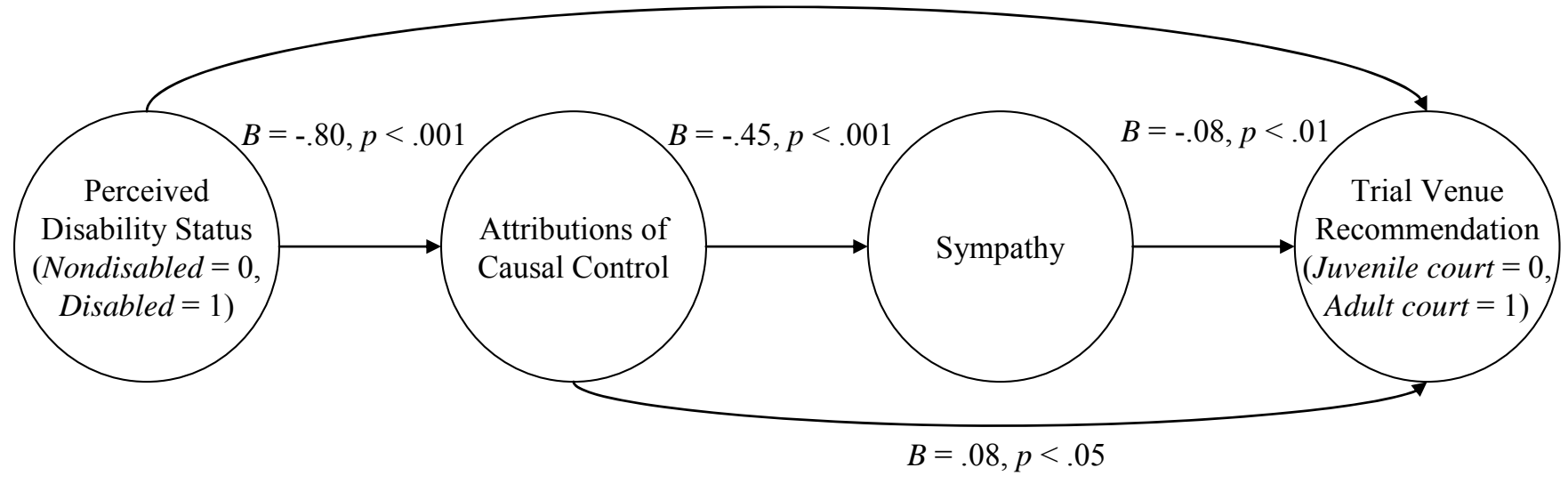

$\chi^{2}(1,209)=2.50, n s, \mathrm{CFI}=.99, \mathrm{RMSEA}=.09$ 